Intersections

Canadian Journal of Music

Revue canadienne de musique
Intersections

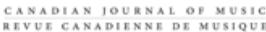

\title{
The Loosening Role of Polyphony: Texture and Formal Functions in Mozart's “Haydn” Quartets
}

\section{Olga Ellen Bakulina}

Volume 32, numéro 1-2, 2012

URI : https://id.erudit.org/iderudit/1018577ar

DOI : https://doi.org/10.7202/1018577ar

Aller au sommaire du numéro

\section{Éditeur(s)}

Canadian University Music Society / Société de musique des universités canadiennes

\section{ISSN}

1911-0146 (imprimé)

1918-512X (numérique)

Découvrir la revue

Citer cet article

Bakulina, O. E. (2012). The Loosening Role of Polyphony: Texture and Formal Functions in Mozart's "Haydn” Quartets. Intersections, 32(1-2), 7-42.

https://doi.org/10.7202/1018577ar
Résumé de l'article

Cet article montre que la texture peut fonctionner comme un facteur déterminant la forme, en se penchant sur le cas de la texture de la polyphonie en imitation, dont les six quatuors de Mozart dédiés à Haydn en sont des exemples. En se basant sur la théorie de la forme fonctionnelle de William Caplin et sur sa distinction entre l'organisation serrée et l'organisation libre, on y montre que la texture peut servir deux objectifs : alléger l'organisation, et créer un contraste de texture et de structure de phrase musicale. Afin de mieux comprendre les rôles formels et expressifs de la polyphonie, on y propose deux nouveaux concepts : la paire contrastante et la présentation en imitation. Le principe de paire contrastante est ensuite exploré dans une sélection de quatuors viennois de contemporains de Mozart.
Copyright (C) Canadian University Music Society / Société de musique des universités canadiennes, 2013
Ce document est protégé par la loi sur le droit d'auteur. L’utilisation des services d'Érudit (y compris la reproduction) est assujettie à sa politique d'utilisation que vous pouvez consulter en ligne.

https://apropos.erudit.org/fr/usagers/politique-dutilisation/ 


\title{
THE LOOSENING ROLE OF POLYPHONY: TEXTURE AND FORMAL FUNCTIONS IN MOZART'S “HAYDN” QUARTETS
}

\author{
Olga (Ellen) Bakulina
}

\section{INTRODUCTION}

Mozart wrote the six quartets dedicated to Joseph Haydn (K. 387, 421, 428, 458, 464, and 465) from 1782 through early 1785, shortly after Mozart had become particularly interested in counterpoint. This interest was prompted by his involvement in 1782 with the music of both J. S. Bach and G. F. Handel, when Mozart attended Baron van Swieten's Sunday afternoon gatherings devoted to the music of these composers. Mozart arranged some of J. S. Bach's fugues for string ensembles and started to write fugues himself-for example, the Fugue in C minor for two pianos, K. 426 (Küster 1996, 133). ${ }^{1}$ The six "Haydn" quartets, published by Artaria in 1785 as op. 10, are the first works of this genre to be composed after this "revolution ... in his creative activity" (Alfred Einstein, quoted by Stanley Sadie 1964, 23). In this essay, I explore the role of counterpoint, for which my preferred term is polyphony, and the interaction between polyphony and formal structure in these quartets. ${ }^{2}$ I show that polyphony acts as a destabilizing force that contributes to the distinction between tight-knit (stable) and loose (unstable) formal categories.

Contrapuntal writing had already had prominence in the genre of the string quartet before Mozart. In general, the fugue retained its importance in the conservative late eighteenth-century Austria, as opposed to other European lands, where fugal writing had gone out of vogue. Haydn's opus 20, for example, contains fugal finales (in nos. 2, 5, and 6). ${ }^{3}$ Other contemporary composers, such as I. Holzbauer, M. Monn, C. Ordonez, and G. C. Wagenseil, wrote

1 In the words of Stanley Sadie $(1964,23)$ Mozart's exposure to fugues gave him "a spell of interest in writing contrapuntally." Indeed, Warren Kirkendale $(1979,162)$ speaks about this time in Mozart's life as "the fugue years."

2 Though the terms polyphony and counterpoint are often used interchangeably, I prefer polyphony for a textural type. Their difference lies in the difference between part and voice. The distinction between parts and voices is analogous to William Rothstein's distinction between notes and tones (1991, 293-5). Polyphony is the relationship between parts, which are literal lines written in the score and performed by different instruments or human voices. By contrast, counterpoint, especially in Schenkerian theory, is the relationship between voices, which are abstract theoretical constructs (for instance, the structural upper voice). Therefore, polyphony is a category of texture, while counterpoint is not.

3 Alfred Einstein ([1945] 1962, 175-77) discusses in some detail the influence of Haydn's fuguefinales in op. 20 on Mozart's quartets K. 168-73. According to him, this influence was at first somewhat unsatisfactory in Mozart's works and reached truly individual creative results only in his "Haydn" quartets. 
fugues in both quartets and other chamber works, as well as orchestral pieces. 4 The eighteenth-century theorist H. C. Koch even argues that "a strict quartet must be in the fugal style" (Mara Parker 2002, 21).5 However, in the works of Mozart's contemporaries, some of which will be analyzed at the end of this paper, movements that are not fully fledged fugues are more often homophonic than polyphonic. Parker (183), who calls the polyphonic quality of quartets a debate, notes that, contrary to a widespread belief, debates are rather rare in the eighteenth-century quartet literature. Furthermore, even when composers do employ polyphony, its role rarely approaches the structural significance it has in Mozart's works. The uniqueness of Mozart's imitative writing lies in the specific kind of interaction he uses between quasi-fugal polyphonic devices and non-fugal forms, such as sonata form, large ternary, and other standardized formal types of the time.

The importance of texture in Classical chamber music, and in the string quartet in particular, has been so widely recognized that one can hardly find a mention of a chamber genre without at least a tangential remark about texture. Several recent studies contribute significantly to the topic of texture in the late eighteenth-century quartets. ${ }^{6}$ Although some of these studies relate form to texture, this association has not yet been scrutinized to the degree it deserves. For instance, little has been done to propose any clearly defined and consistently found structural role that texture can play along with other musical dimensions such as harmony, tonal design, or rhythm.7 Within the remarkably animated discussion of form in the last couple of decades, texture has certainly played an implicit role, though it has not assumed major significance. In particular, texture influences such notions as Caplin's (1998) evaded cadence, the accompanimental overlap, and premature dominant arrival, James Hepokoski and Warren Darcy's (2006) medial caesura, and William Rothstein's (1989) lead-in. ${ }^{8}$

4 In eighteenth-century Vienna, the fugue was important not only compositionally, but also theoretically (Fux's Gradus was published there in 1725). See Kirkendale (1979) on the social and compositional role of fugue in Viennese music of the time. As both Sadie $(1964,24)$ and Kirkendale $(1979$, 163) note, however, complete fugues differ substantially from fugues (or fugatos) included in sonata movements. One finds the latter in K. $387 / \mathrm{iv}$, to be analyzed in this essay. Reginald Barrett-Ayres (1974, 122-26) emphasizes the connections between fugues by composers of the time.

5 Edward Klorman $(2013,28)$ emphasizes that Koch's main idea is not so much fugal style itself, but rather the dominance of textural exchange. This broadening of the textural norm in the quartet, however, includes textures other than polyphony, since in some cases the parts exchange the leading role quite rarely, such as every few measures.

6 See Maud Alice Trimmer (1981); Mara Parker (2002); and Dean Sutcliffe (2003). All three works concentrate specifically on texture in quartets. Janet Levy 1982 is a more general study of texture and is not confined to any particular stylistic era. Ben Duane's (2012) and Edward Klorman's (2013) dissertations engage in analysis of texture in eighteenth-century quartets.

7 A work that proposes a structural function of texture is Wallace Berry (1976). He devotes a separate section to the role of texture in form: "Texture ... is of course an essential element by which thematic statement is rendered distinctive and expressive" (236). His analytical remarks show how changes of texture (density, type, etc.) delineate formal boundaries. Though he recognizes the structural importance of texture, in this section he carefully avoids any examples from common-practice music, with the exception of a quintet by Brahms.

8 See Olga Bakulina (2010, 20-21) for more on textural significance of these concepts. 


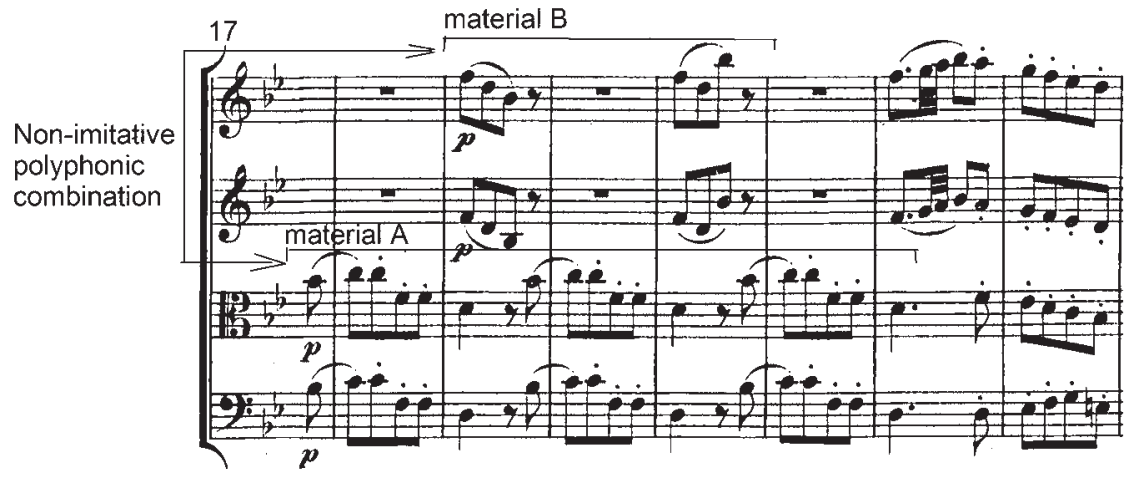

Example 1. Types of polyphonic quartets and their potential for contributing to loose formal structures.

(a) Non-imitative polyphony: W. A. Mozart, String Quartet in B-flat Major, K. 458/iv, mm. $17-24$

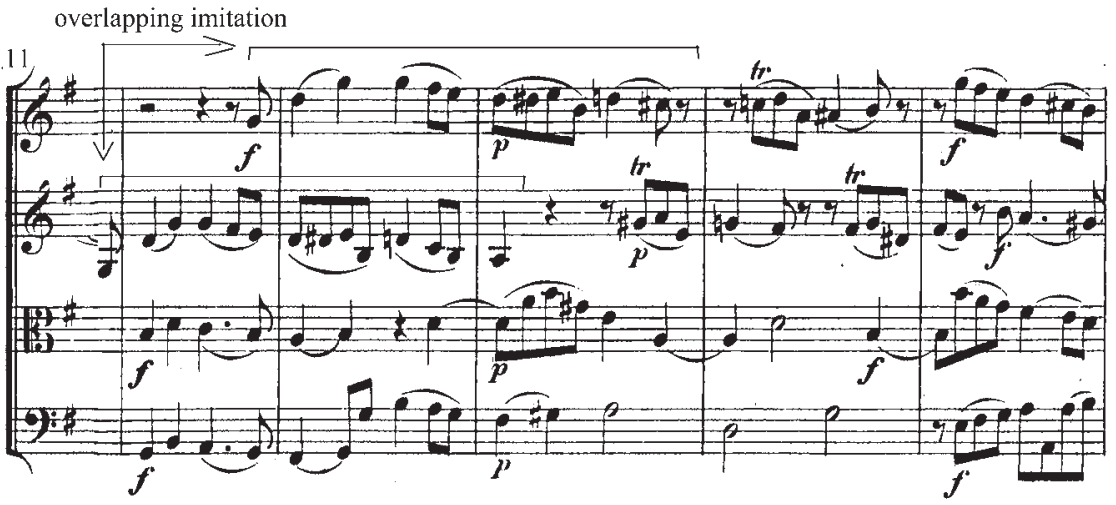

(b) Overlapping imitative polyphony: String Quartet in G Major, K. 387/i, mm. 10-13

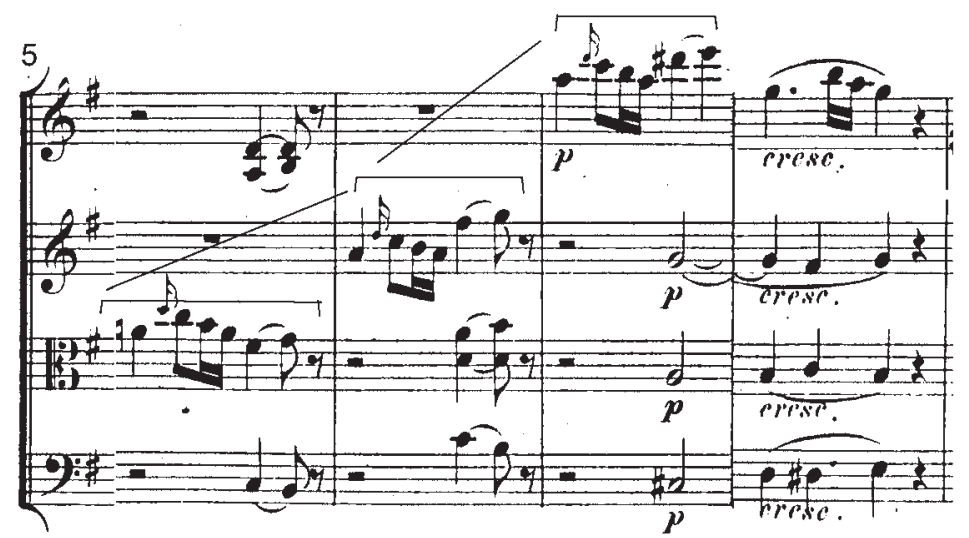

(c) Non-overlapping imitative polyphony: String Quartet in G Major, K. 387/i, mm. 5-8 
The purpose of the present article is to propose that texture does have a structural function as related to form. Relying on Caplin's theory of formal functions, I use his concept of looser formal structure-formal destabilization-to show that the texture of imitative polyphony is a strong indicator of formal loosening. ${ }^{9}$ Metrical conflicts created by imitations are among the strongest means of such a loosening. Therefore polyphonic texture most often appears in formal areas that normally require loose structure - that is, the medial formal functions ${ }^{10}$ Moreover, polyphony helps to create contrast between two formal sections that display similar motivic material but differ in formal organization and texture. Such pairs of formal sections are termed contrast pairs. They may be found at one level of form-functional hierarchy (simple pairs) or at multiple levels simultaneously (embedded pairs). The notion of contrast pair helps us to examine the formal logic and expressive force of Mozart's pieces; in many instances, the most polyphonically dense passages are also the ones that possess the highest rhetorical intensity and indeed serve as a climax, whether local or global (for the entire movement).
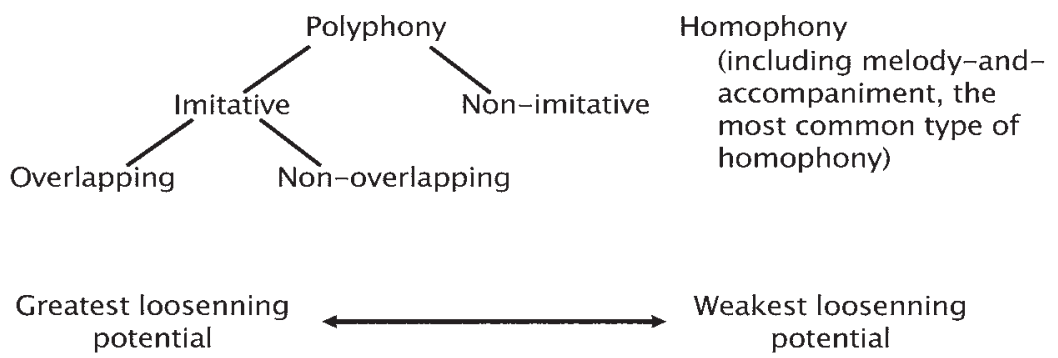

Figure 1. Types of texture in Mozart's quartets and their potential for contributing to loose formal structures

This study focuses on formal areas other than the development section of the sonata form, because the use of imitation in non-developmental areas is less predictable than in developmental. The core section of a Mozart development is very often imitative, whereas in other formal regions, such as the exposition, imitative polyphony can occur at various points. ${ }^{11}$ This relative unpredictability is precisely our concern. I finish by exploring the contrast-pair principle in select Viennese quartets by Mozart's contemporaries: Carl Dittersdorf, Joseph Haydn, and Johann Baptist Vanhal. In all of the examples, including those

9 Loose formal structure (Caplin's term) is the destabilization or weakening of tightly knit formal types such as period or sentence. The main characteristics of loose form are modulation, sequence, chromaticism, asymmetrical grouping structure, and non-conventional formal types. See Caplin (2009).

10 Medial functions include the transition and subordinate themes among the theme functions, as well as the continuation and contrasting middle (and also sometimes consequent) among the phrase functions. See Caplin (1998) for a fuller explanation of this classification.

11 This refers to all the instrumental genres in which Mozart worked, not only the string quartets. 
by Mozart, I concentrate on movements that are not fugues but are written in one of the standard Classical formal types and only include fugal or other polyphonic elements. Though Caplin's theory serves as the conceptual basis for this study, I will refer at times to concepts from Hepokoski and Darcy's sonata theory, to compare different analytical possibilities of the same musical excerpts.

My purpose is to explore the relationship between texture and form, and not texture as an isolated notion. Therefore, rather than propose a detailed typology of textures, I will give only a general definition of polyphony and its several broad categories crucial for a study to form-texture relationships. Figure 1 summarizes these categories. By polyphony, as distinguished from homophony, I understand a texture with more than one line of melodic individuality and structural independence. ${ }^{12}$ This independence consists of the line's rhythmic, melodic-directional, phrase-structural, or metric profile contrasting with other simultaneous lines at any given stretch of time. Polyphony is further classified as imitative and non-imitative. Imitative polyphony may be either overlapping, where each following voice enters before the previous voice has finished playing the melody that is imitated, or non-overlapping, in which one voice comes in with a melody upon the end of this melody in another voice. Example 1 provides instances of the three types of texture relevant to the following analytical examples. Example 1a shows two textural strands, upper and lower, featuring different motivic content; $1 \mathrm{~b}$ has a melody imitated by the two violins and shifted in time; and ic features a short motive imitated twice without a temporal overlap. It is the imitative subcategory that primarily concerns us here.

\section{FORM-TEXTURE RELATIONSHIP: TEXTURE AND FORMAL PROCESSES}

Let us now see how various textural types relate to formal structure. I first consider the distinction between tight-knit and loose types of formal organization. I then show that imitative polyphony serves as one of the factors responsible for loose organization through the mediation of grouping structure and hypermeter.

The concept of tight-knit and loose formal structure, which originated in the theories of Arnold Schoenberg and Erwin Ratz, has received considerable development in Caplin's functional theory. ${ }^{13}$ The concept concerns formal processes rather than formal types and refers to phrase-structural instability, asymmetry, and unconventional grouping. ${ }^{14}$ Table 1 (based on Caplin 2009) lists the musical parameters that are characteristic of tight-knit or loose-knit

12 Though the individuality of a melodic line is often a matter of individual judgment, one can broadly understand it as certain independence of a melody from others sounded at the same time. Brent Auerbach $(2008,278)$ offers to see such independence as "a function of listener attention span."

13 Schoenberg (1967) introduces his notions of fest (tight) and locker (looser) formal structures in his Fundamentals of Musical Composition; these notions were further developed by Ratz (1973).

14 On the distinction between formal types and formal processes, see Caplin (1998, 9; 2009, 30-34). 
organization. The key aspects that indicate loose form are modulation, sequence, chromaticism, asymmetrical grouping structure, and non-conventional formal types. Although not incorporated in table 1, Caplin $(1998,75)$ also mentions various textural devices, particularly imitation, as one of the loosening factors of the contrasting middle of a small ternary. However, polyphonic texture, especially overlapping imitations and certain contrapuntal devices, such as canonic sequence, is a powerful organizational force that promotes loose structure.

Table 1. Table of Musical Aspects That Contribute to Tight-knit and Loose Organization

Tight-knit

Home key, prolongation of tonic, diatonic harmony, strong cadence (PAC), symmetrical grouping structure, uniformity of motivic material, thematic conventionality (period or, slightly less tight-knit, sentence)

Loose

Distant keys and modulation, sequences, chromatic harmony, cadential evasion or absence of cadence, asymmetrical grouping structure, diversity of motivic material, non-conventional formal types

Based on Caplin $(2009,38)$

Table 1 illustrates that grouping structure is a primary factor used to distinguish between tight-knit and loose formal organization. Caplin $(1998,9)$ defines grouping structure as "a hierarchical arrangement of discrete, perceptually significant time spans ... [E]ach group ... can be identified most neutrally in terms of its measure length." At the smallest hierarchical level-that is, the phrase level-the groups are melodic and harmonic passages with a perceptible beginning and end. To establish the beginning and ending point between groups, one needs a more or less clearly articulated boundary between the two. This boundary can be a caesura of some kind, such as a longer note value or a rest. As Ratz (1973) explains, simultaneous rest points are essential for homophonic texture. ${ }^{15}$ But caesuras are not the only defining aspect here; a boundary can be heard, for example, when a phrase is immediately repeated, in which case a group is perceived as "the next one" as soon as a repetition has started. ${ }^{16}$ Using the terms of Fred Lerdahl and Ray Jackendoff (1983), who theorize grouping structure in a very detailed way, grouping preference rule (GPR) 6 is at work here: the similarity, or parallelism, between two or more melodic segments renders these segments two separate groups. ${ }^{17}$

Example 2a provides an illustration of a clearly pronounced grouping structure. In this melody, one can easily comprehend the first two measures as one

15 Ratz $(1973,44)$ says, "For homophonic writing, it is characteristic to have ... caesuras achieved through half and authentic cadences (where all the voices cadence simultaneously and in the same manner at the end of each section, in contrast with polyphony where such a cadence happens in principle only at the end of a piece)" (translation mine). Here he refers to caesuras as cadences, but it is possible to understand caesura in a broader way and on various hierarchical levels, from the smallest phrase level to the largest sections of a movement.

16 It seems relevant here to allude to a term proposed by Koch in his Versuch, written at about the same time as Mozart's "Haydn" quartets: Ruhepunkt des Geistes. By this, Koch means a perceived, but not literally present, rest or caesura between two adjacent phrases, a kind of perceptual pause, without any notated pause in the actual music (Koch [1782-93] 1983, 1).

17 The exact definition of GPR 6 reads: "Where two or more segments of the music can be construed as parallel, they preferably form parallel parts of groups" (Lerdahl and Jackendoff 1983, 51). 


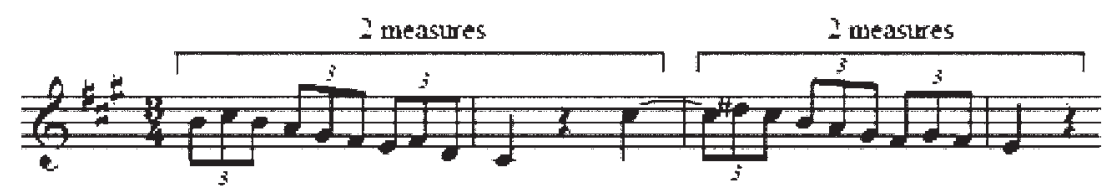

Example 2. Mozart, String Quartet in A Major, K. 464/i, mm. 49-52

(a) The second violin part

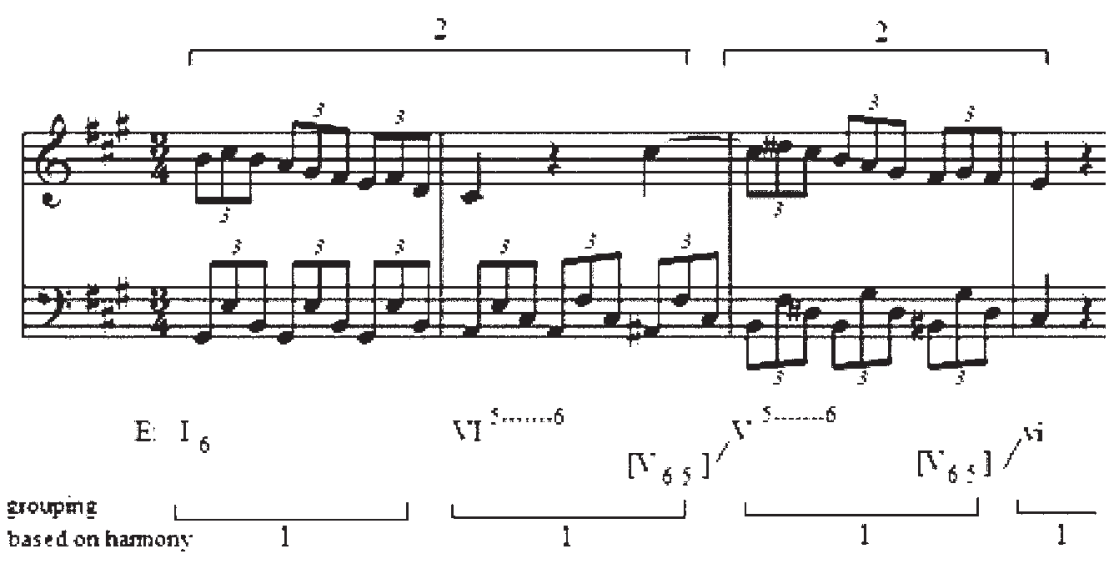

(b) The second violin part: A homophonic recomposition

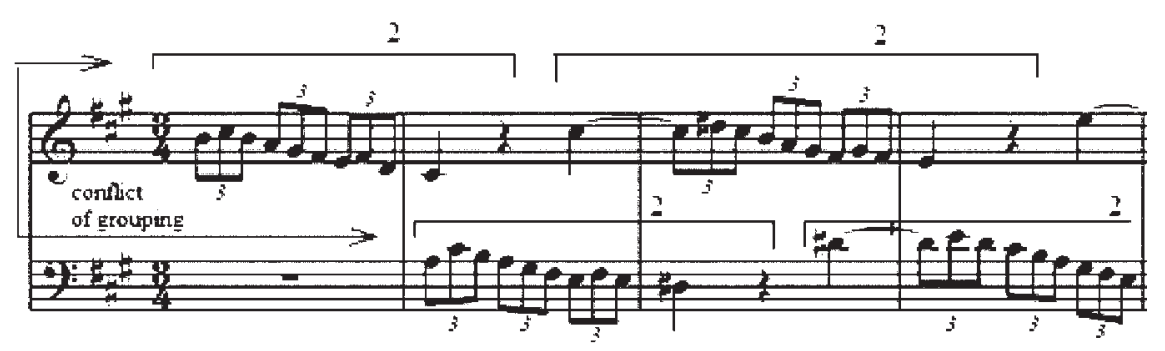

(c) The second violin and viola parts

group and the second two as another group, with the syncopation slightly shifting the beginning of the second group (which would normally start on the downbeat of $\mathrm{m}$. 3). Let us now imagine this melody hypothetically in a homophonic texture, resembling that of a piano piece, as in example $2 \mathrm{~b}$. Although the added voice does not exactly coincide rhythmically with the principal voice, its rhythm gives no new grouping details and so remains in the structural purview of the soprano line. However, the added voice does provide some new information, namely harmony, that can affect our perception of the line's grouping structure: The linear 5-6 motion and the resulting sequence, in which the model is one bar long, adds a one-bar-group "feeling" to the two-bar grouping of the melody. 
The grouping is always more challenging in imitative vs. homophonic textures, as a result of the temporal conflicts between imitative parts. If, for example, one adds another part that plays the previously examined melody shifted in time by one measure (example 2c), the two parts enter in conflicting temporal relations: the second violin groups $\mathrm{mm} .2$ and 3 , with the expectation that measures 4 and 5 will also be grouped together, while the first violin has the opposite grouping-mm. 1 and 2, then $\mathrm{mm}$. 3 and 4. Each part has its most active segment at the time when the other part finds itself at rest. As a result, the phrase boundary in one part conflicts with that in the other; in other words, the beginning of a group is found at different temporal points in two different voices. It is certainly possible to hear one of the two imitative voices-for example, the $d u$-as defining the grouping of the passage and the other voice as subordinate: the same refers to the hypermetrical conflict between the two voices, to be addressed below. Nonetheless, the grouping conflict resulting from the imitation is always perceptible and produces a loose formal situation.

Finally, in the actual passage in Mozart's quartet (example 2d), one finds two additional parts set against the ones we have been considering. These additional voices further obfuscate the grouping structure because there are no caesuras and their quasi-imitative relationship. Moreover, the four voices providing full harmonies, the grouping conflicts of the two-bar units in individual melodies enter into an even more complex relationship with the one-bar sequential structure of the harmonic progression.

Another instance of conflicting grouping structure in a two-voice combination is found in the canonic sequence in example 3. Again, two parts, the violins, each contain a two-bar grouping structure and conflict with each other as a result of the temporal shift of the imitative combination. This instance is also further complicated by harmonic structure-the descending-fifth sequencein which each harmony takes one measure and thus suggests a one-bar grouping structure against the conflicting two-bar grouping of the top voices. Moreover, the harmonic progression alone contributes to the loose character of the passage since, according to Caplin, sequences are a primary loosening technique (see table 1$).^{18}$

In addition to a grouping conflict, we also find a hypermetric conflict in the two-voice imitative examples (examples $2 \mathrm{c}$ and 3 ). If, for instance, we adopt a beginning-accented hypermetrical pattern at the two-measure level in each voice in example $2 \mathrm{c}$, we will hear $\mathrm{mm} .1$ and 3 as accented in the $d u x$, while the comes has the opposite accentuation-mm. 2 and $4 .{ }^{19}$ An end-accented hypermetrical version of the two-measure motive (second measures of the group as a hyper-downbeat) gives the opposite result: now the odd measures are accented

18 Unlike all my other examples, this is a development section, and thus the passage is formally loose.

19 Danuta Mirka (2009, 189) discusses this metrical conflict as a displacement dissonance, which she calls imitations "per thesin et arsin," adopting the terms introduced by the eighteenthcentury theorist Wilhelm Marpurg. 
by the comes. ${ }^{20}$ Using Joel Lester's distinction between various metric levels (Lester 1986), we can speak of this conflict being produced at the level of the dotted half notes: the upper part groups these notes beginning in $\mathrm{m}$. 1, while the lower part begins in m. $2 .{ }^{21}$

In listening to passages similar to the ones just examined, one's perception of grouping and metre may rely on different musical attributes. For instance, one may hear the two imitative voices as the source of temporal conflicts, thus implying that the two possess equal importance in creating the grouping structure of the passage. Alternatively, one can also hear the $d u x$, as determining the grouping structure, while the other voices, being "led" by the first, are metrically subordinate to it. Another possible approach is to rely on the hypermetre created by the harmonic motion and not by any individual voices. ${ }^{22}$

Perhaps the best description of elusive sense of temporal conflicts in imitations arises in shadow metre, a term coined by Frank Samarotto (1999) and subsequently developed by Rothstein (1995). Shadow metre is a metrical pattern different from, and heard at the same time with, the dominant pattern. According to Rothstein $(1995,167)$, "a shadow meter is a secondary meter formed by a series of regularly recurring accents, when those accents do not coincide with the prevailing meter (or hypermeter)." In the case of examples $2 c$, the violin is metrically dominant and the viola provides an alternative simultaneous metrical pattern-a shadow metre. The same happens in example 3, where the leading metrical role belongs to the first violin, by virtue of its temporal primacy, and the shadow metre is found in the second violin. In both examples, the shadow metre might be called more specifically an imitative shadow. ${ }^{23}$

To briefly summarize, imitative polyphony contributes to loosening formal structure, and the relationship between texture and form is mediated by

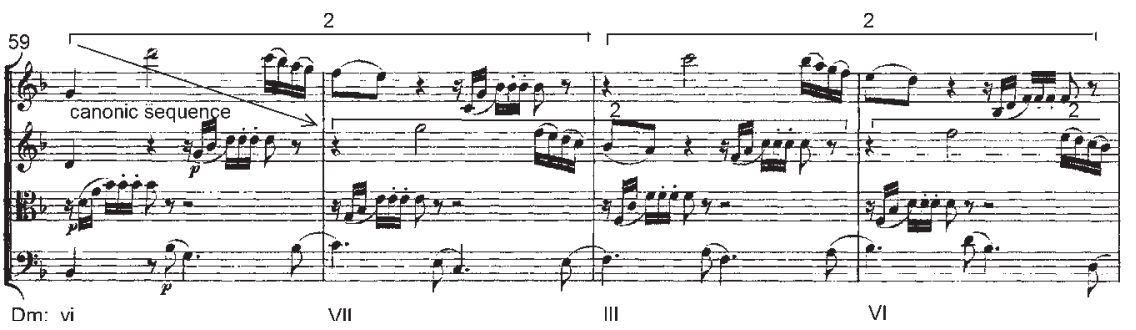

Example 3. Mozart, String Quartet in D Minor, K. 421/i, mm. 59-63

20 Hyperdownbeat, Jonathan Kramer's term, denotes an accented timepoint within a hypermeasure. Put differently, it is a measure that functions as a downbeat at a hypermetrical level (Kramer 1988, 86).

21 It should be noted that, in non-imitative polyphony, hypermetrical conflicts are generally less aurally significant than in imitative. Many examples can be found in the slow movements of Mozart's quartets, where a dominating melodic line is supplemented with other melodies that conform to the metrical profile of the main line.

22 To rely on the hypermetre created by the harmonic structure, as opposed to the individual parts, would be the preferred approach of most Schenkerian analysts.

23 Of course, the part that enters first is not absolutely always hypermetrically strong. Other factors can determine hypermetrical strength of a beat, but in the majority of cases, the $d u x$ is indeed placed at a hypermetrically strong moment. 
grouping structure and hyper-metre. To associate the concept of tight-knit/ knit-loose form with musical expression, imitative polyphony signals instability and often actively participates in the building of a climax. I will now turn to specific examples of how Mozart uses the loosening potential of polyphonic texture in his "Haydn" quartets.

\section{Texture and formal functions: Polyphony as a means of CONTRAST}

Both of the imitative passages examined so far appear in medial formal regions: example $2 \mathrm{~d}$ is the continuation of a subordinate theme; and example 3 is a development section. In fact, Mozart uses imitative texture in medial formal regions quite frequently. ${ }^{24}$ Thus, from the form-functional viewpoint, imitative polyphony behaves the same way as do other loosening techniques that, according to Caplin $(1998,17)$, characterize medial functionality at various hierarchical levels, such as continuations (at the phrase level), transitions (at the thematic level), and developments (at the full-movement level). Sometimes one finds imitative texture in concluding regions, especially at the theme level-in the subordinate theme. ${ }^{25}$ Conversely, the initial function, stable and tight-knit by definition, rarely contains polyphonic elements. ${ }^{26}$

A close reading of the quartets shows that, with regard to motivic content, polyphonic medial regions almost always employ previously stated material. As opposed to the first statement, tight-knit, homophonic, and belonging to an initial function, the second statement is normally looser and polyphonic and belongs to a medial formal function. I will refer to such pairs of motivic statements as contrast pairs. Table 2 provides the scheme of a contrast pair. Thus, motivic return usually produces imitative polyphony; and vice versa, imitations signal a motivic return. An important aspect of a contrast pair is the thematic initiation of the first (stable) component.

Table 2. Scheme of a Contrast Pair Based on Three Dimensions of Each of the Two Components: Formal Functionality, Internal Formal Organization, and Texture

\begin{tabular}{llll}
\multicolumn{1}{c}{ Material } & Formal functionality & $\begin{array}{c}\text { Internal formal } \\
\text { organization }\end{array}$ & Texture \\
\hline First statement & Initial & Tight-knit & Homophonic \\
Second statement & Medial or concluding & Loose & Polyphonic \\
\hline
\end{tabular}

Certainly this representation of the contrast-pair principle is very schematic; not every pair exhibits the same degree of absolutely discrete formal and textural types. Rather, this is an abstract model to which some specific examples conform in greater degree than others. The stronger the formal and

24 As I will show later in this study, the use of imitative polyphony in medial formal regions is not limited to Mozart's output; it is quite typical for many of his contemporaries' music.

25 Caplin $(1998,17)$ categorizes the subordinate theme as the concluding function within the entire sonata exposition, where the main theme is the initial function and the transition is the medial.

26 The imitative presentation, a polyphonic initial section, to be defined below, is an exception to this rule. 
textural opposition between the constituents of a pair, the more these components express the abstract contrast-pair principle.

The main theme and the transition of the quartet K. $387 / \mathrm{i}$ (example 4) exemplify a typical contrast pair. ${ }^{27}$ The main theme, the hybrid type 3 , begins with a four-measure compound basic idea (c.b.i.), presented in a chordal texture in which the first violin is the leading part. ${ }^{28}$ The main theme represents a normative tight-knit theme type; the deceptive cadence represents a small departure from a tight-knit model. The transition, in contrast, is more sophisticated and unstable. It restates the basic idea of the main theme in the second violin, while the first violin imitates the melody at the one-measure time interval, creating an overlapping imitation. The result is an imitative presentation, a polyphonic subtype of the presentation function. ${ }^{29}$ A loose situation is thus immediately created and strongly sets the transition in opposition to the stable and tightknit main theme. The following continuation phrase augments the instability by featuring a canonic sequence in $\mathrm{mm} .13-14$, a fragmentation process, and harmonic instability (note the chromatic line in imitation in m. 16-20). All this activity produces remarkable intensification, which resolves at the half cadence in $\mathrm{m} .20$.

This first example shows an imitative formal region, the transition, which restates thematic material previously introduced homophonically. Let us classify this type of a contrast pair as a simple, theme-level contrast pair; the term simple distinguishes it from the "embedded" type, to be discussed in the following example. One finds simple main-theme/transition pairs very often in the quartets; most of the examples include imitative presentation in the second member of a contrast pair.

Before proceeding with the next analysis, a pause is appropriate to define an imitative presentation. Essentially, the term denotes a polyphonic type of the presentation function in sentential designs. As defined by Caplin (1998, 35), a presentation phrase consists of a two-bar basic idea and its immediate repetition, often with harmonic and/or melodic modifications. In the quartets explored here, many repetitions are achieved by placing the same idea in different parts, with an overlap between subsequent voices. The defining feature of an imitative presentation is the absence of a clearly perceived boundary between the basic idea and its repetition. The formal organization of an imitative presentation is always looser than that of a usual presentation. An imitative presentation is among the more effective loosening devices in the quartets, and therefore appears only in those regions that are usually unstable in their formal

27 To economize space, I will refer to movement numbers by a slash and a roman numeral after the Köchel number; so, for example, K. $387 /$ i signifies "first movement of the quartet K. 387 ."

28 Hybrids are tight-knit formal types that combine the traits of period and sentence. For the classification of hybrids, see Caplin (1998, 59-63).

29 This presentation can also be viewed as an expanded basic idea (b.i.): the b.i. in mm. 11-12 expanded through the imitation in $\mathrm{mm}$. 12-13. However, I prefer the imitative presentation view, since this presentation type is common for transitions and frequently serves for various metric and formal deviations such as extensions and compressions, while a compressed b.i. occurs much less often and is rather an exception in the quartets. 
Example 4. Mozart, String Quartet in G Major, K. 387/i, main theme and transition
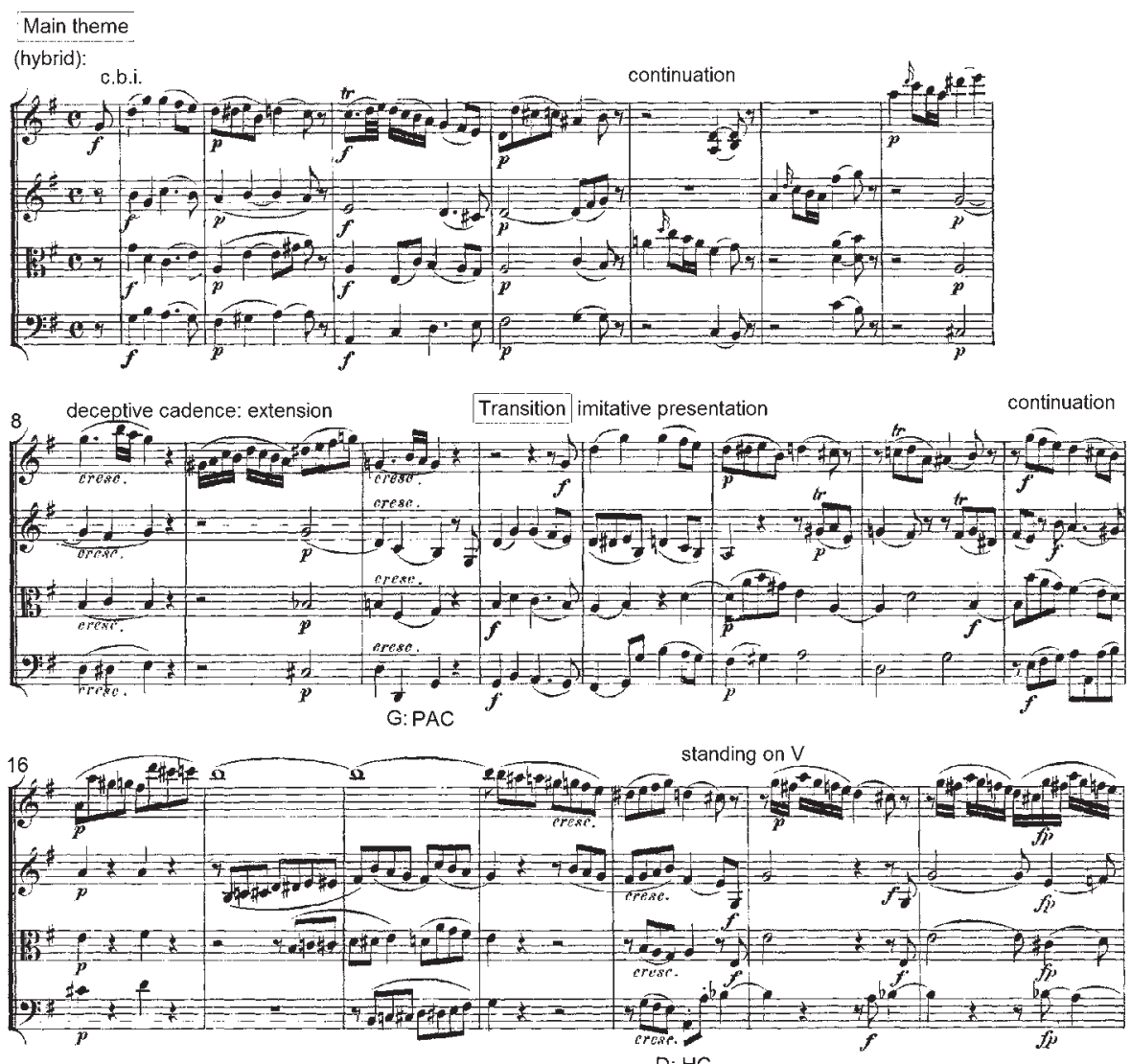

Example 4. Mozart, String Quartet in G Major, K. 387/i, main theme and transition

organization-transition and subordinate theme. I will show more imitative presentations in the analyses to be presented below (see examples 5, 6, and 8).

Returning to the analytical examination of contrast pairs, in K. 465/i (the so-called Dissonance Quartet), example 5 offers another theme-level contrast pair. The main theme, organized as a compound period, consists of two sentences, the second of which is extended. The texture is a classic instance of homophony. The formal, textural, and metrical stability of this theme is juxtaposed with the much more destabilized transition ( $\mathrm{mm} .45 \mathrm{ff})$. The latter builds an imitative presentation based on the main theme material. The basic idea is imitated by all the parts in the ascending order, from the cello to the first violin, and all of them "flow into" the continuation, also densely polyphonic, without any caesura..$^{30}$

This example, however, shows a more complex structure than do all the previous examples. If we consider the cello part beginning in $\mathrm{m} .31$ a countermelody

30 Klorman $(2013,212)$ calls this imitative entry of all the parts a "module of patterned activity," which, in his view, is an example of Lerdahl and Jackendoff's MPR $5 \mathrm{~d}$ (pattern of articulation). 

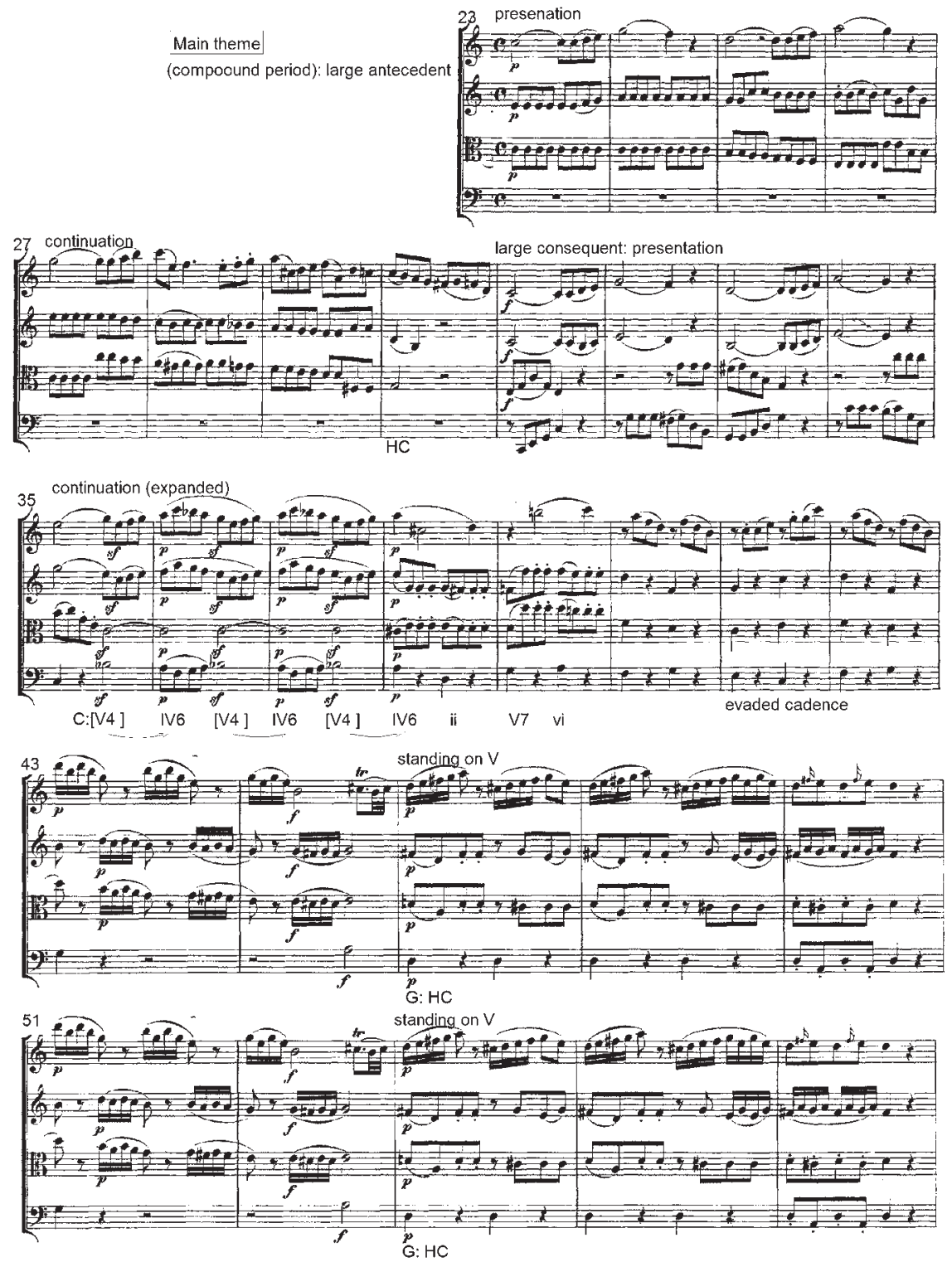

Example 5. Mozart, String Quartet in C Major, K. 465/i, main theme and transition.

to the first violin, and thus a polyphonic element, we are faced with a lowerlevel contrast pair within the main theme, between the completely homophonic antecedent and the slightly more polyphonically developed consequent. In this case, this quartet presents an embedded contrast pair-one that operates at the phrase level and at the theme level simultaneously. Figure 2 summarizes this structure. 


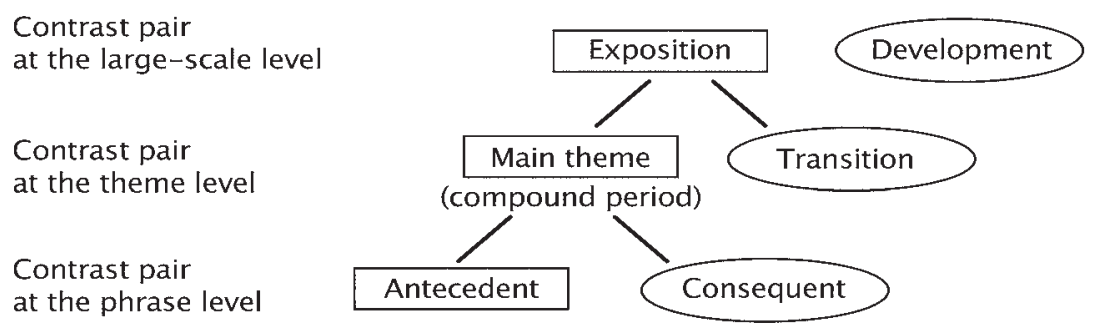

Figure 2. Scheme of the embedded contrast group in K. $465 / \mathrm{i}$

Having examined some theme-level contrast pairs, I now turn to groups of three thematic units, built on the same principle of textural and form-functional contrast. Such groups are found in the so-called monothematic movements, those in which the main and subordinate themes share the same material. Interestingly, the pair comprising main-theme/subordinate-theme almost never occurs alone in the "Haydn" quartets: the two themes are always mediated by another section, the transition..$^{11}$ This yields three formal sections following each other and employing the same material; that material is given a progressively looser embodiment with each new occurrence.

Example 6, K. 464/iv, is one of such instances. ${ }^{32}$ Although the main theme contains some polyphonic attributes (the two violins in the continuation phrase), they do not contribute to any instability of formal structure. The theme exhibits a compound, sixteen-measure sentence with no phrase-structural, harmonic, or other loosening elements. In contrast, the transition shows more signs of loose structure. Although its presentation (mm. 17-24) preserves the symmetrical, eight-measure stricture, it contains imitations of the basic idea in the second violin and viola, thus acquiring some elements of an imitative presentation. The following continuation brings three different canonic sequences that blur the metric grid almost to the point of losing a sense of downbeat. The presentation and the continuation thus form a phrase-level contrast pair embedded within the large-scale contrast group of the themes. The subordinate theme also assumes a loose character: it starts with an imitative presentation of five (!) bars, ${ }^{33}$ which is immediately repeated, and further destabilizes the

31 Strictly speaking, the transition, according to Caplin (1998), is not a "theme"; only the main and subordinate regions receive the theme status. But since the transition occupies the medial position between the initial main theme and the concluding subordinate, the function of the transition is "interthematic": at the theme level, as opposed to the phrase level.

32 One of the most recent commentaries on this movement is Ivanovitch 2010. Ivanovitch explores the recursive elements-elements of repetition-in the generally goal-oriented motion of sonata form. He contends that the remarkable motivic economy of the movement, its mono-thematicism, contributes to its recursive nature.

33 In Hepokoski and Darcy's terms, the MC in m. 39 is somewhat problematic: only the upper part has a true caesura, while the other parts continue to play past this moment. In case one does not hear $\mathrm{m} .39$ as an MC, m. 40 does not launch the S, and the exposition if continuous. On continuous exposition, see Hepokoski and Darcy (2006, 51-64). 
Main theme (compound sentence)

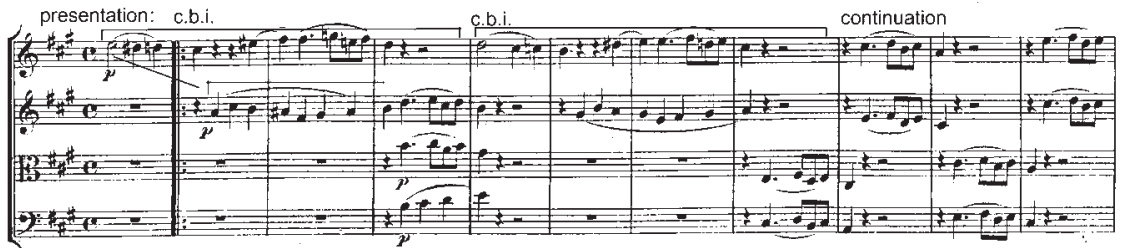

Transition

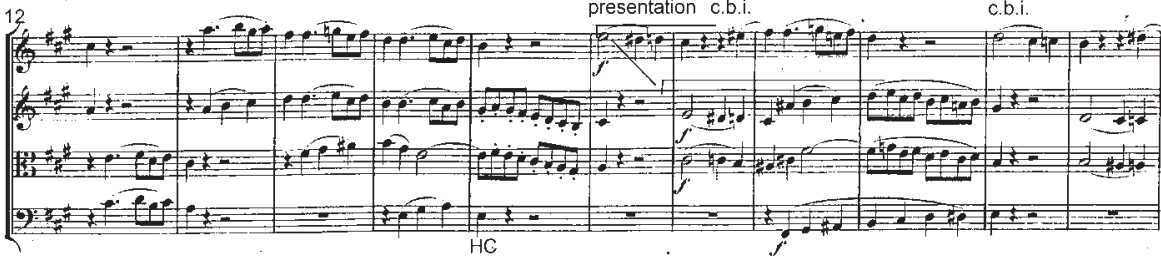

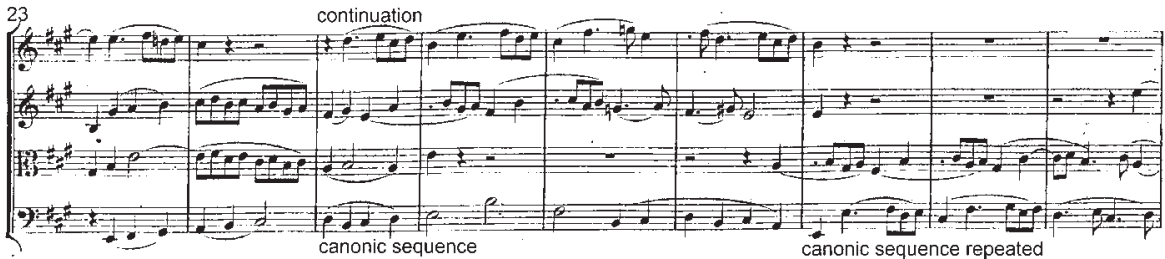

standing on $V$ : canonic sequence
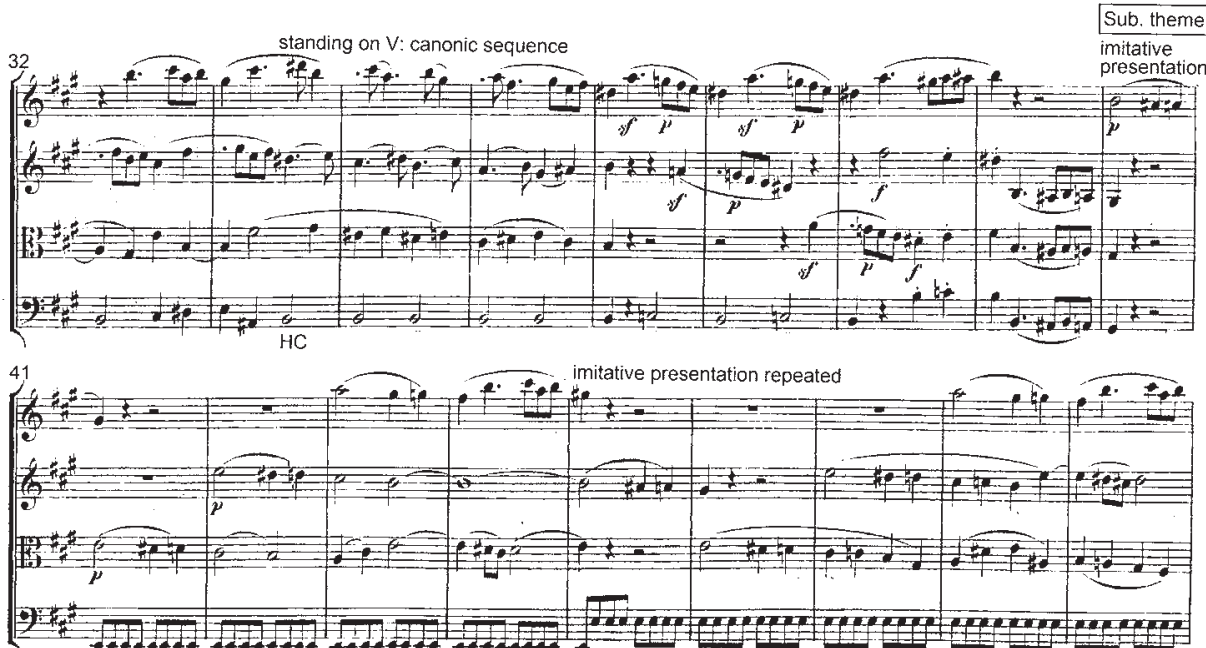

Example 6. Mozart, String Quartet in A Major, K. 464/iv, main theme, transition, and subordinate theme (cont'd on next page). 


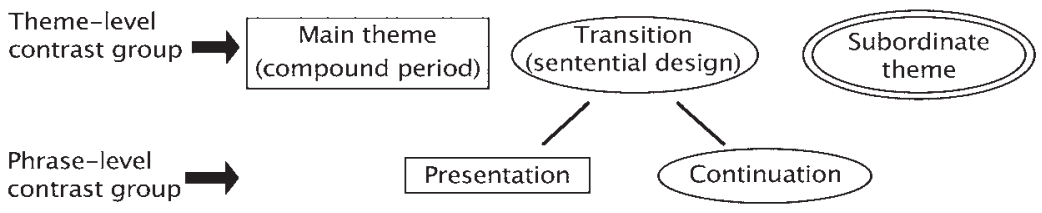

Figure 3. Scheme of the embedded contrast group in K. 464/iv

music by intense fragmentation (one-bar segments in the melody). ${ }^{34}$ Figure 3 summarizes this contrast group at both the phrase and the theme level.

The contrast groups discussed so far feature a main theme as their first, stable constituent, largely because the main theme is normally the most tightknit theme in a sonata exposition. I will now show several less typical instances where the first theme of a subordinate theme group fulfils the function of the stable constituent of a pair; the second theme develops the material and loosens the structure of the first. In all of these instances, the first subordinate theme introduces new material, rather than borrowing it from previous sections; the situation supports the idea of thematic initiation being essential for constructing a contrast pair. ${ }^{35}$

K. 464/i (example 7) presents such a contrast pair within the subordinate group. The first theme of the group (mm. 37-44), an eight-measure hybrid type 4 (c.b.i. plus consequent), seems almost too simple both formally and texturally. The second subordinate theme (mm. 45-61) restates the original basic idea in the second violin, but now it serves as a basis for an imitative presentation. Although the second violin dominates melodically and metrically, its conflict with the first violin nonetheless produces some destabilization in comparison with the preceding theme. This destabilization is heightened in the continuation phrase. ${ }^{36}$ The time interval of imitation continuously decreases in the three upper parts, until the passage finally reaches the cadential phrase $(\mathrm{m}$. 58). In this passage, extraordinarily, the $3 / 4$ metre breaks down almost completely (only the slurring in the first violin continues to support the notated $3 / 4$ metre). The chain of suspensions in the second violin and viola suggests 2/4 articulation; the same is true of the sequential pattern in the first violin. ${ }^{37}$ The unmediated juxtaposition of the two themes enhances their structural and

34 In some sense, the subordinate theme restores stability by introducing imitations at the time interval of a full measure, which provides more metrical clarity than the transition does, especially in its continuation phrase.

35 Contrast pairs formed by two subordinate themes fall under the category of "theme and expanded variant" in Hepokoski and Darcy's terms. In this type of the S, the strategy is to "launch S as a simple parallel period, sentence, or other brief, closed structure ... and then to submit it to florid, expanded version" (Hepokoski and Darcy 2006, 129). This technique, as they acknowledge, is especially typical for Mozart.

36 This continuation is analyzed in example $6 \mathrm{~d}$ to show the grouping-structure conflicts produced by imitative texture.

37 Thanks to Edward Klorman for bringing to my attention, in a private conversation, this metrically unusual quality of the passage. 

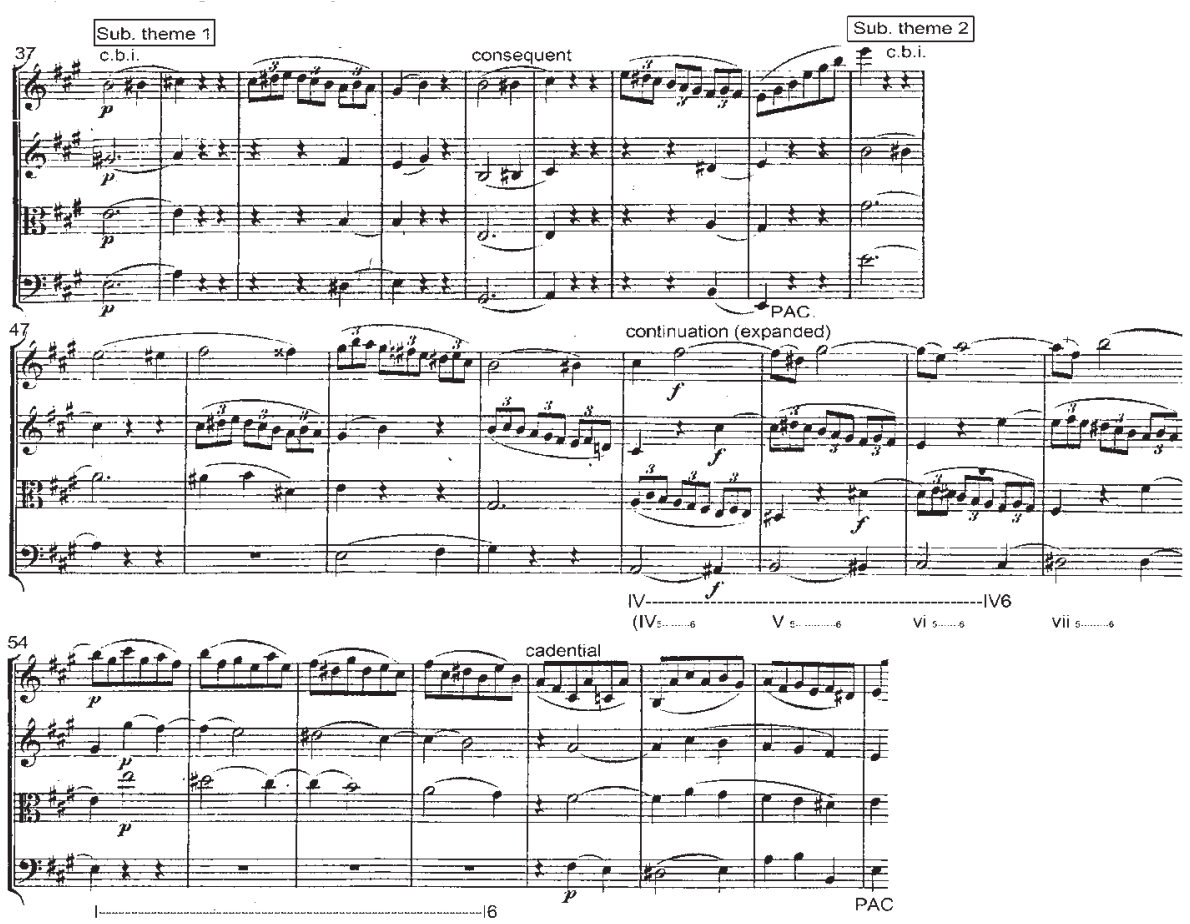

Example 7. Mozart, String Quartet in A Major, K. 464/i, subordinate theme 1 and 2

rhetorical contrast. ${ }^{38}$ A similar situation-two subordinate themes creating a contrast pair-occurs in K. 428/iv, not shown here: in this instance, the second constituent (subordinate theme 2) displays non-imitative polyphony and thus is considerably more stable in phrase structure and metre.

As any definition based on strict conceptual distinctions, the definition of contrast-pair is somewhat rigid, as opposed to the flexibility of actual musical practice. The following two examples may be viewed as testing the boundary of the definition. In them, at least one aspect of the contrast-pair principle, presented in table 2, is absent or weakened. Nonetheless, these instances offer a useful way to explain two sections sharing the same motivic material.

K. 428/i, example 8, exhibits two such sections: the transition and the subordinate theme. The transition (mm. 12-23), in its continuation phrase, introduces a motive that initially does not attract attention, the descending motive in the first violin, mm. 20-22. Following the half cadence in m. 24, the subordinate theme employs the same motive to build an imitative presentation (mm. 24-8).39 The transition features a thin, generally homophonic texture, although a short non-imitative dialogue takes place among the upper parts

${ }^{8}$ By two themes, I mean the first and second constituents of the subordinate group, not two different motivic entities.

39 In Hepokosky and Darcy's terms, m. 24 is not a subordinate theme yet. Rather, this exposition displays a trimodular block: $\mathrm{m}$. 24 does not offer an $\mathrm{MC}$ and thus does not usher in the S; then a V:PAC MC comes in m. 40, whereupon the S is launched. Caplin $(1998,274 n 16)$ views this exposition 


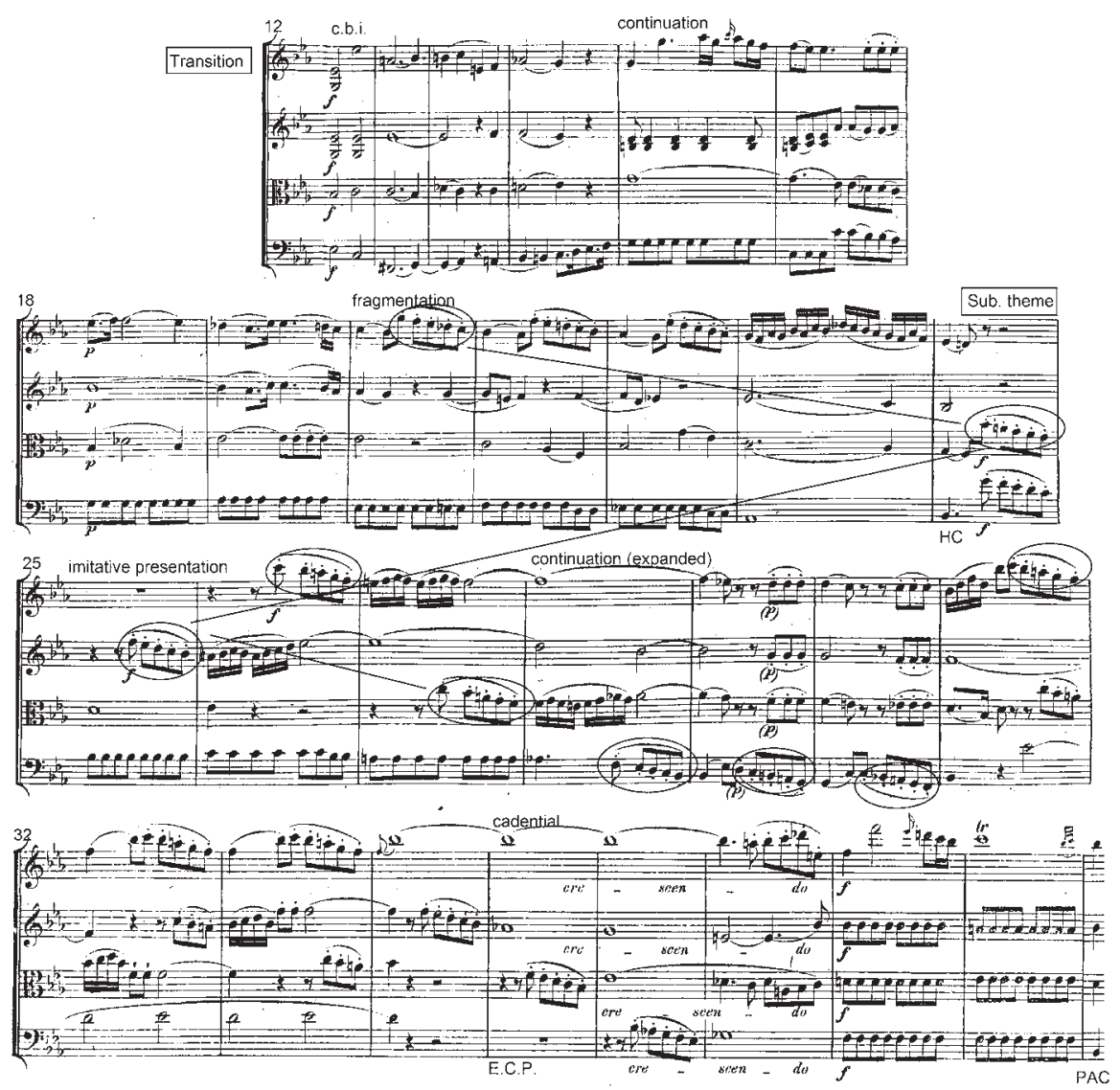

Example 8. Mozart, String Quartet in E-flat Major, K. 428/i, transition and subordinate theme

(mm. 20-22). The texture of the imitative presentation contrasts with the preceding music and emphasizes the subordinate theme as substantially richer in both metre and phrase structure. The rest of this theme develops the descending motive imitatively until well into the cadential phrase (m. 36). I see this pair as exceptional, primarily because the first constituent, the transition, by definition neither tight-knit nor stable, normally destabilizes the structure and heightens the expressive force of the music. Therefore the opposition tightknit/loose is lacking in this pair (although the textural contrast of homophony/ polyphony is present).

A final example draws from the famous fugal finale to the quartet K. 387 ; the fugal setting makes it even more unusual. ${ }^{\circ}$ The movement is in sonata form, in which each of the major thematic groups is built as a fugal exposition.

as having a non-modulating transition (mm. 12-24), since no subsequent event offers an HC or dominant arrival required to end the transition; in my own analysis, I prefer this reading.

40 Hepokoski and Darcy $(2006,139)$ give this movement as an example of the "learned-style S." While this is true, they do not mention that the $\mathrm{P}$ is also in the learned style, i.e., fugal. It is this rela- 
a) Main theme, mm. 1-14.

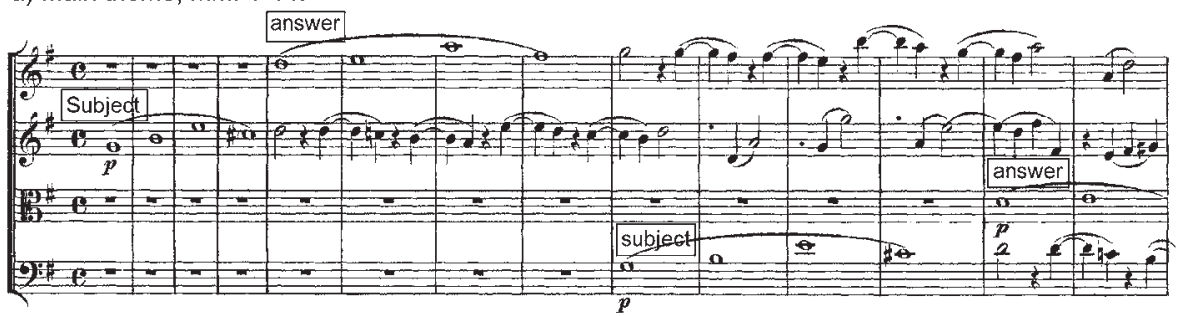

b) Subordinate theme, $\mathrm{mm}$. 52-91

S1 = subject of the first subordinate theme;(S2) = subject of the second subordinate theme

52
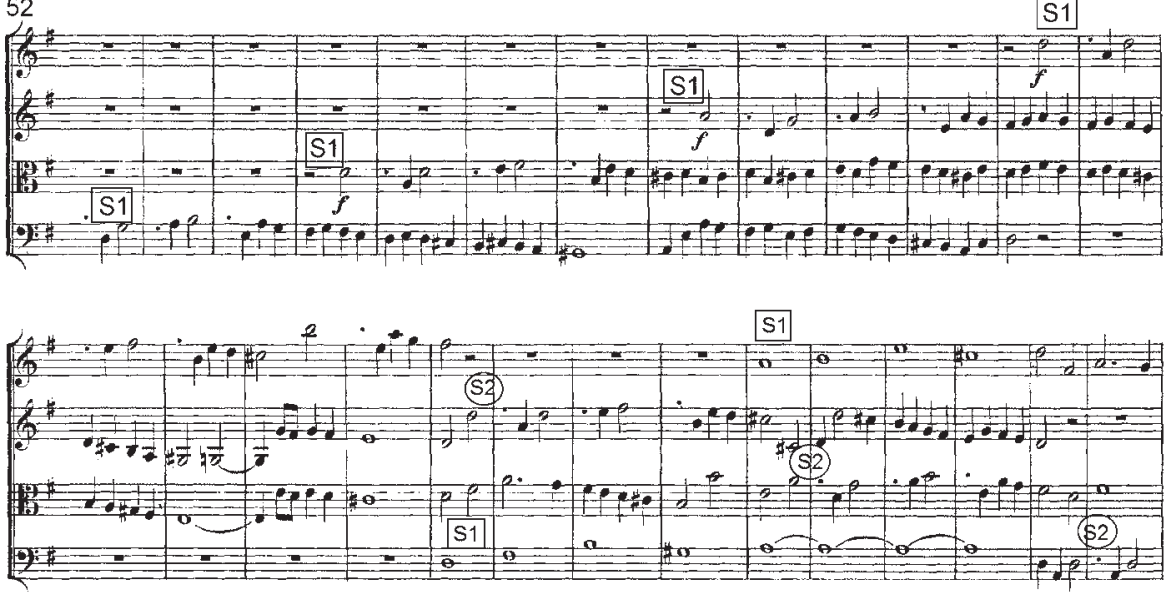

(52)

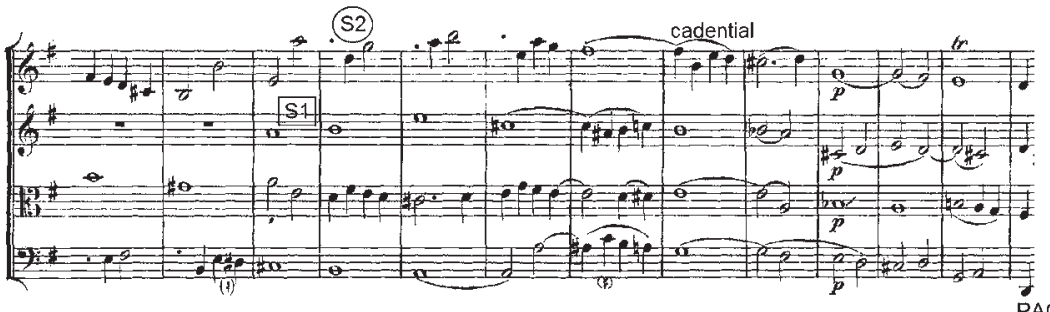

Example 9. Mozart, String Quartet in G Major, K. 387/iv

The main theme (example 9a) includes four entries of a four-note subject; the transition uses imitative texture as well, but does not create any standard polyphonic form; and the subordinate theme (mm. 52-91, example $9 \mathrm{~b}$ ) returns to the fugal principle-however, this time it is a double fugue, which starts with a new subject (mm. 52-70) and later brings back the subject of the main theme. ${ }^{41}$

tionship of the two themes that makes the movement particularly ingenuous. Mirka (2009) discusses this movement in relation to tactus and topic.

41 Using Schubert and Neidhöfer's definition, this is the third type of double fugue, the type that first displays only one subject, then introduces another one late in the piece (Schubert and Neidhöfer 
The two themes, therefore, share the same material-the subject of the main theme.

This motivic relatedness of the two themes allows us to view them as a contrast pair, although, in the absence of conventional Classical formal types, we must rely on other formal criteria derived from fugal form. Compared to a single-subject fugue, a double fugue is a more contrapuntally complex and a less predictable formal type, in the same way that a loosely organized Classical theme is more complex and less predictable than a tight-knit one. The use of fugal passages in a sonata movement like this one offers us a rare opportunity to compare two different kinds of musical logic-Baroque and Classical. Just as in a Baroque fugue, Mozart writes his fugal subjects for future contrapuntal possibilities, but these possibilities are realized at important formal junctures that highlight the formal principles of late eighteenth-century music.

\section{The CONTRAST-PAIR PRINCIPLE: BEYOND MOZART}

The period during which Mozart composed his "Haydn" quartets witnessed a florescence in string quartet writing. In the remaining portion of this article, I will examine some of the quartets written in Vienna roughly at the same time by Dittersdorf, Haydn, and Vanhal. ${ }^{22}$ In their works that I will discuss, though polyphonic texture is often significant, its structural function differs from that in Mozart, although Haydn gradually progressed towards more consistent use of polyphony similar to Mozart's. 43

With the exception of Haydn's later quartets, contrast pairs are rather rare in the works of these three composers. Imitative polyphony retains its formfunctional significance-that is, it usually comes in medial formal regionsbut usually lacks motivic importance, so significant for Mozart. Motivic return rarely produces imitative polyphony, and vice versa: imitations rarely signal motivic return.

These points are especially apparent in two scenarios: when previously used material comes back without polyphony and when polyphony is used without motivic restatement. Haydn's quartet op. 20, no. 3/iii (example 10), illustrates the first circumstance. Here, the main theme features a melody in the first violin, the lower parts providing harmonic support. The theme ends with an IAC in $\mathrm{m} .8$, followed by a repetition of the same material. While initially one might perceive this as the consequent of a potential sixteen-measure period, it soon moves away from the home key and proves to be a transition. With their shared material, the two sections-the main theme and the transition-provide

2006, 162).

42 Parker (2002) is one of the few scholars who have analyzed the quartets of Mozart's contemporaries; her approach, however, is decidedly non-analytical with regard to form. I have chosen these three composers and not others because of the close connections between them. Haydn, Dittersdorf, Mozart, and Vanhal performed quartets together in the mid-1780s (Parker 2002, 43-44).

43 Haydn's increasing use of polyphony has been noted before (Parker 2002, 279), but I wish to show that it is not only a matter of amount of polyphony, but rather the specific method of using polyphony that distinguished Haydn's later quartets from his earlier ones. After Mozart's "Haydn" quartets had been written, Haydn himself (starting with op. 50) began to employ the contrast-pair principle more consistently than he did before. 

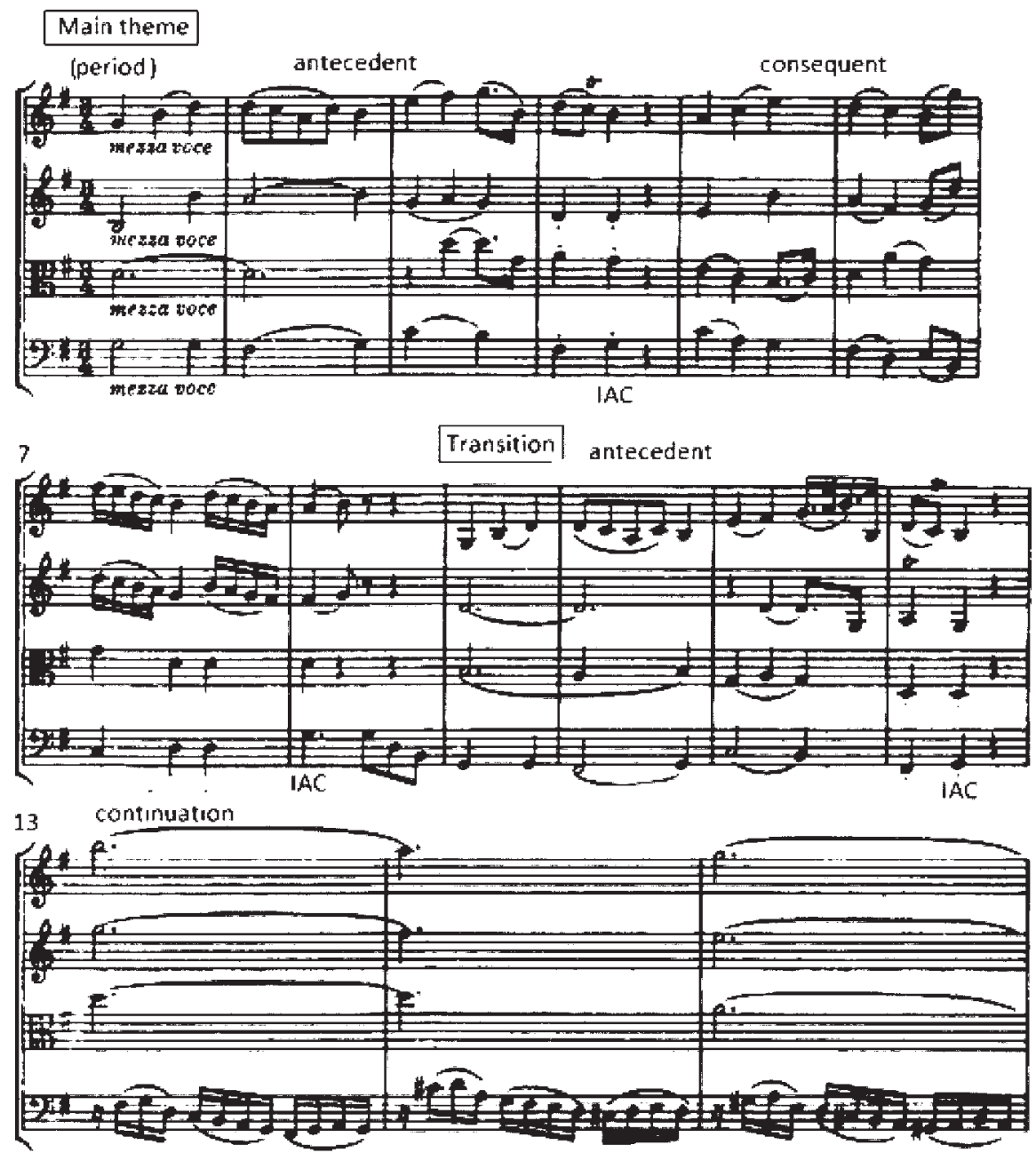

Example 10. J. Haydn. String Quartet in G Minor, op. 20, no. 3/iii, main theme and transition

perfect conditions for building a contrast pair at the thematic level. 44 And yet, Haydn uses none of the textural devices that would produce such a pair: the transition begins with the same chordal texture that was used previously, with no polyphonic elements. The continuation phrase of the transition (m. 13ff) changes the relationship between voices: the cello now becomes the leading part, but once again no ensuing polyphony appears. In this example, Haydn is evidently interested in processes other than motivic restatements with contrasting textures, the principal feature of a contrast pair.

44 Had Haydn written a contrast pair at the theme level, main-theme/transition, the example would have been very similar to Mozart's K. $387 /$ i, shown in example 4 . 
Main theme (compound sentence)
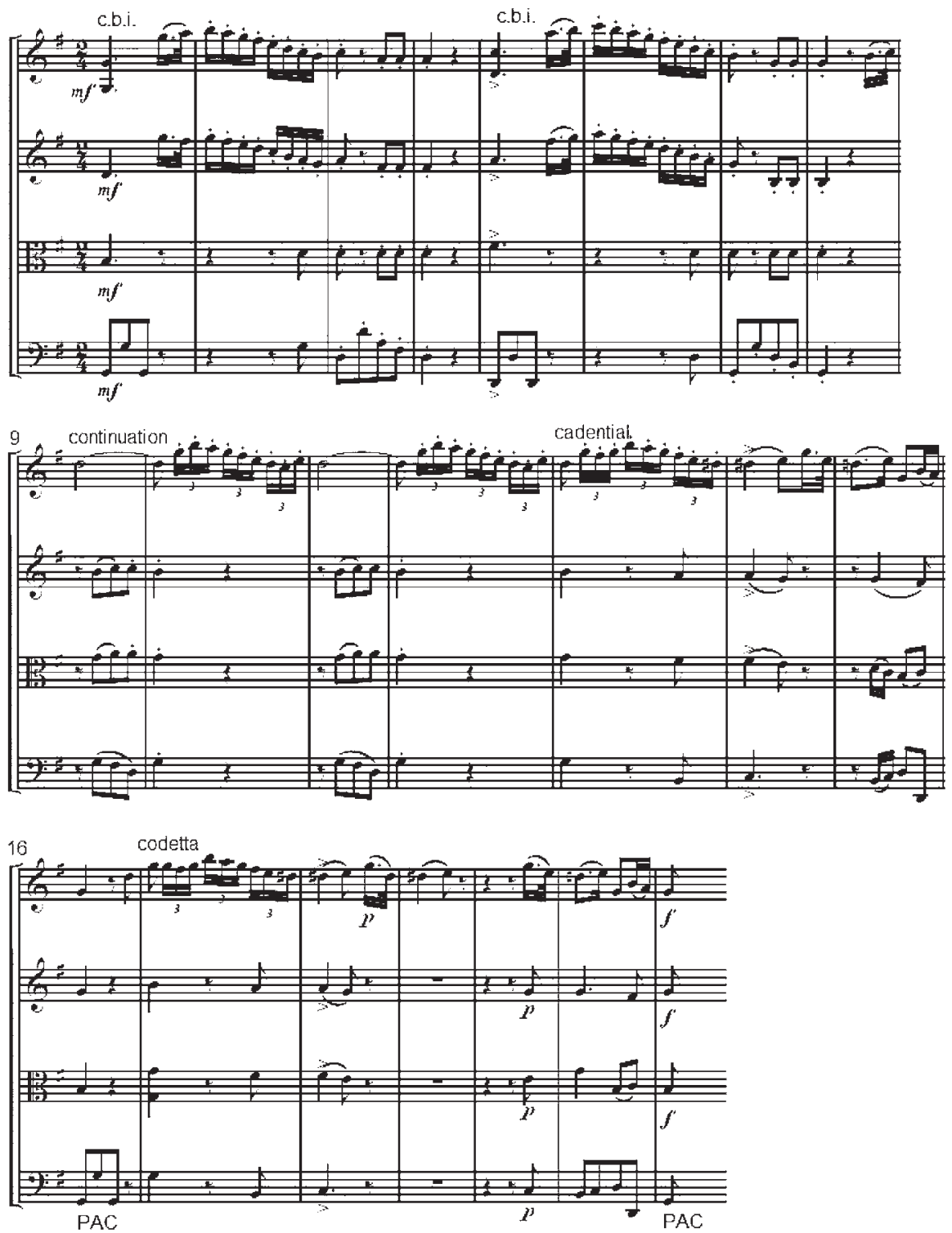

Example 11. J. B. Vanhal, String Quartet in G Major/i, main theme

An analogous design appears in other composers' works. For instance, the main theme from the first movement of Vanhal's Quartet in G Major (example 11), main theme, displays a sixteen-measure compound sentence, where the continuation (mm. 9-16) features a scalar motive in the first violin related to the line of the upper parts in the c.b.i. These two phrases, the initial (presentation) and the medial (continuation), share the scalar motive and, therefore, 
create ideal conditions for a phrase-level contrast pair. Vanhal, however, does not avail himself of the opportunity: both phrases contain homophonic textures. The gaps between the motive statements in the subordinate theme $(\mathrm{mm}$. 9 and 11) provide imitative opportunities of the same motive in another part, but are left almost "blank," with minimal chordal filling. The texture type throughout the main theme as a whole is what Parker terms a lecture; note that this texture continues in the codettas of the theme (mm. 17-22) and in the subsequent transition. ${ }^{45}$ Although the first violin is now joined by the second, there is no imitative texture. In fact, in Vanhal's output of quartets, imitative or other polyphonic textures are rather rare in general. ${ }^{46}$ Vanhal's Quartet in C Major (example 12) provides a comparable illustration with example 11. The main theme is homophonic and formally tight-knit: it exemplifies the hybrid 1 type (antecedent plus continuation). In the subordinate theme (12b, mm. 30 and 34), the first violin restates a motive from the continuation of the main theme (12a) without altering its homophonic texture. Both themes therefore are also instances of Parker's lecture, with the lower parts providing modest accompaniment. Thus, the example shows an opportunity for a contrast pair, but the composer does not avail himself of this opportunity.

The second category of weak contrast pairs finds the use of imitative texture outside of motivic restatements. The majority of such cases occur in formal areas in which polyphonic textures are normative, such as medial or concluding regions at either phrase or theme level. To illustrate, consider Dittersdorf's Quartet in D Major, no. 1/i (example 13a). Here, since the second subordinate theme begins with a canonic sequence, this c.b.i. resembles an imitative presentation. 47 After the IAC, a continuation follows with more canonic activity. All these polyphonic phrases use new material (see example 13b). One might intuit two potential contrast pairs here. For instance, the opening of this theme could have restated the material from the main theme and so create a pair main-theme/subordinate-theme-that is, a theme-level pair. Further, one might imagine the continuation of example 13a borrowing the material from the presentation and thus building a phrase-level pair presentation/continuation. Yet Dittersdorf uses new material in both cases. Instead of creating contrast pairs, his compositional purpose might be to provide an impression of freshness and ingenuity by giving a new theme of a lively character produced by imitative texture. The technique of polyphonic motivic restatement, however, is totally absent here. ${ }^{48}$

45 According to Parker $(2002,57)$, lecture is a type of texture in which the first violin dominates melodically.

46 Parker $(2002,184-87)$ gives a list of "debate" quartets-those where polyphonic texture dominates. Vanhal's quartets are nearly absent there (only three of his works appear in this list). Conversely, in her list of "lecture" quartets ( $78-83)$, those where the texture is homophonic, Vanhal appears ten times.

47 For Hepokoski and Darcy, this would not be a second subordinate theme (a term they do not use, in fact), but the only subordinate theme, since the cadence in $\mathrm{m} .43$ is the first and only option for an MC.

48 Other examples of imitative passages based on new motivic material: Dittersdorf, the slow movement Quartet no. 1 (where the contrasting middle contains an imitative section); Quartet no. 5 in 
a) Main theme (hybrid)
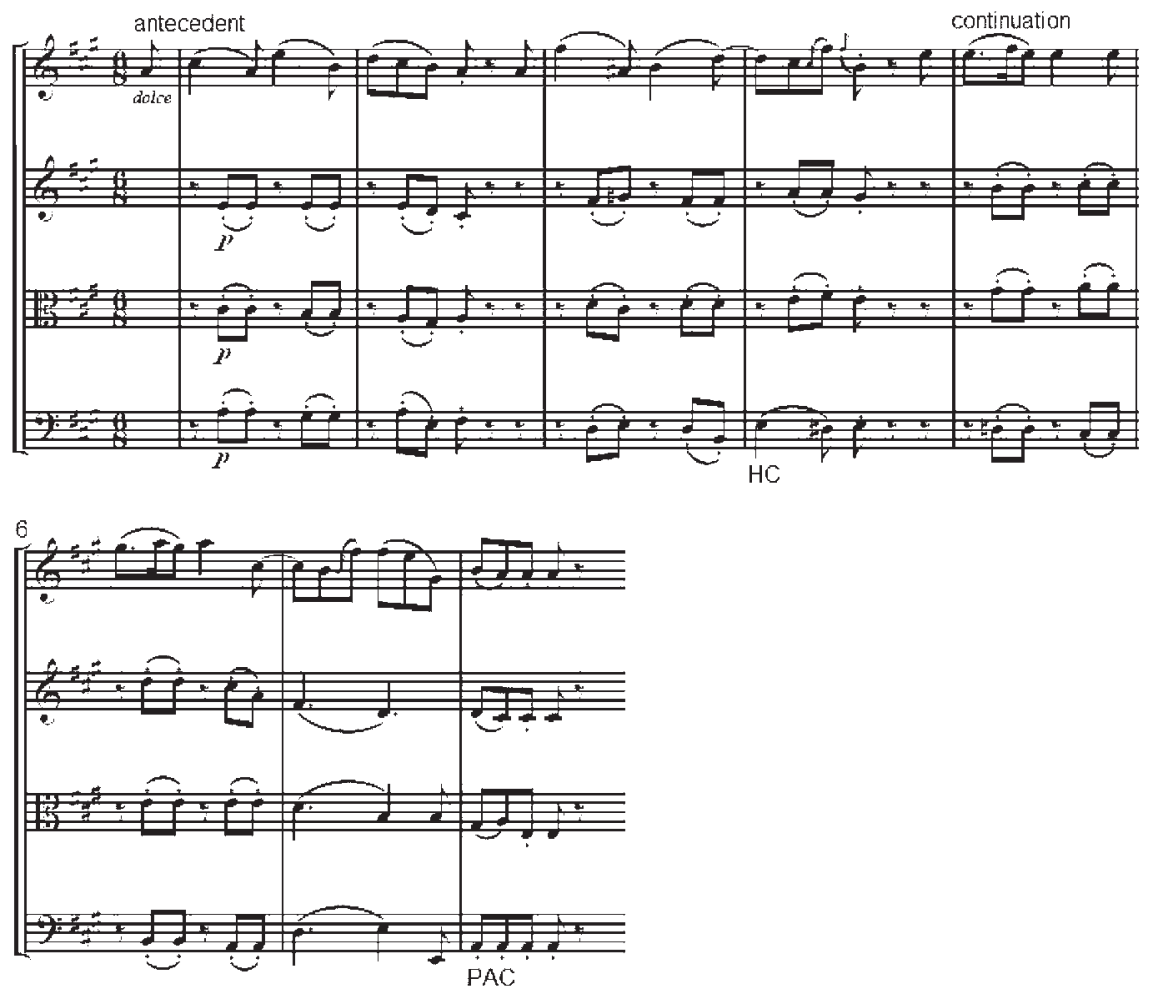

b) Subordinate theme

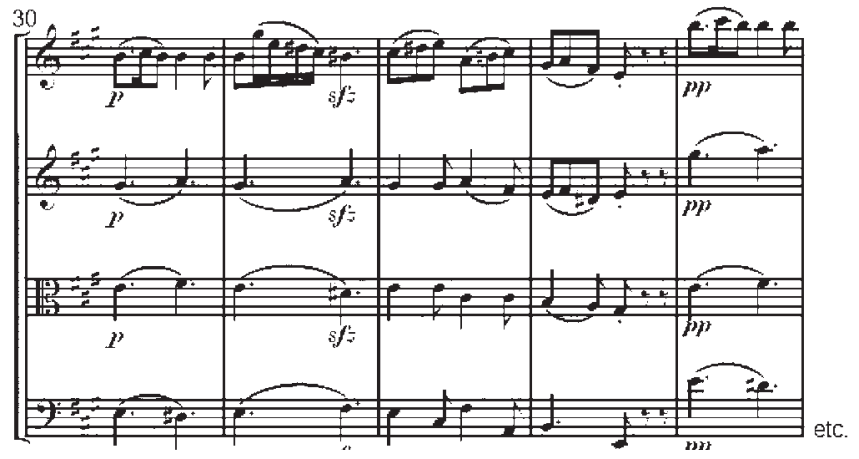

Example 12. Vanhal, String Quartet in A Major/i, main theme and subordinate theme 
a) Second subordinate theme
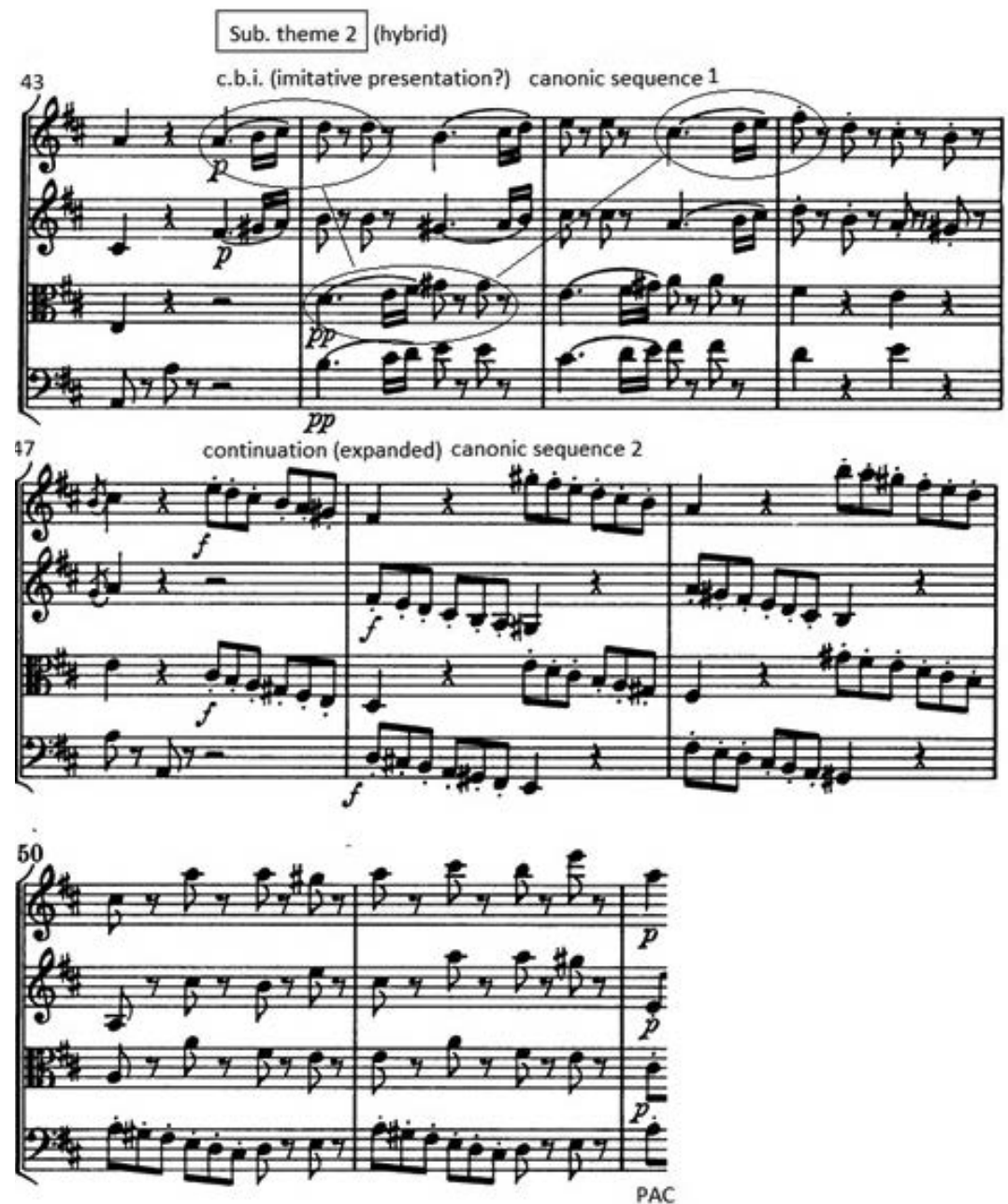

b) Main theme (opening)

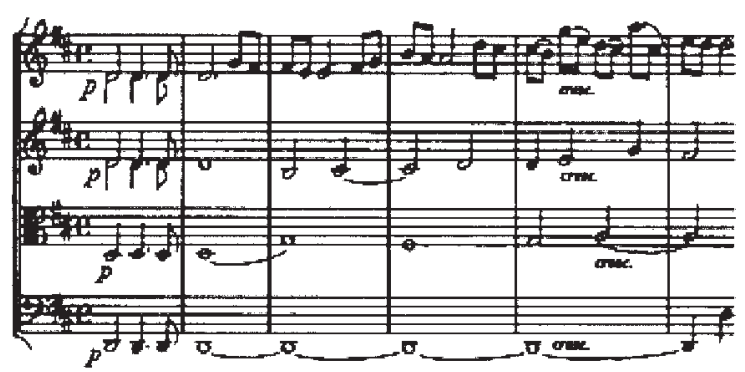

Example 13. C. Dittersdorf, String Quartet No. 1 in D Major/i 
Despite the relatively weak interest in contrast-pair logic in the examples shown above, one nevertheless finds some instances in the works of Mozart's contemporaries. Naturally, some cases exhibit the principle more rigorously than others. In Dittersdorf's Quartet in B-flat Major, no. 2/i (example 14), one can perceive (albeit with some strain) a theme-level contrast pair (main-theme/ transition). The main theme, with its strict homophonic, introduces the b.i. material, with its prominent ascending sixth, in the first violin. The transition, elided with the main theme, begins with a canonic sequence, in which the second violin leads; formally, one interprets an imitative presentation followed by a continuation. As always, the canonic sequence produces a grouping and hypermetrical conflict between the two upper voices. ${ }^{49}$ This conflict significantly adds to the instability of the transition, when compared with the homophonic and hypermetrically stable main theme. The melodic proximity of the two themes, however, is equivocal and rests more on rhythmic than motivic similarity. Both themes feature passages with a prominent sixteenthnote motive (which begins with a tied note). But the main theme's opening ascending sixth is practically absent in the transition, except for $\mathrm{m}$. 8, second violin, where the motive is found slightly below the surface (the first and third note of the measure). $5^{\circ}$ In sum, example 14 approximates the ideal contrast pair, but lacks an unequivocal motivic restatement. ${ }^{1}$

Haydn's op. 33, often described as the principal inspiration for Mozart's "Haydn" quartets, contains relatively few contrast pairs; imitative textures, though sometimes present, do not dominate in these works. Op. 33, no. 2/i (example 15) contains another main-theme/transition pair. ${ }^{52}$ This example is somewhat similar to the previous one, by Dittersdorf, in that the main theme, in a small ternary form, is tight-knit, homophonic, and generally very stable. 53

E-flat Major, movement 1 (where the subordinate theme features a canonic sequence in the continuation, based on material that is not particularly related to any preceding material); Vanhal, Quartet in C Major, movement 1 (the end of the fused transition-subordinate theme is imitative, based on a new motive opening with a repeated note); Haydn, Quartet op. 20, no. 1/i, subordinate theme (the continuation phrase is imitative).

49 As always, an imitative grouping conflict produces a metrical conflict. The second violin accentuates even-numbered measures, and the first violin accentuates odd-numbered measures. This hypermetric structure is based on the attacks on the downbeats of odd-numbered measures in the second violin (MPR 3 in Lerdahl and Jackendoff 1983) and an absence of an attack on the downbeat of even-numbered measures. The first violin offers the opposite accentuation. The harmony, with stable tonic chords in mm. 8, 10, and 12, supports the dux's even-strong hypermeter (MPR 9).

50 I use the word surface in a Schenkerian sense here. Surface-the literal content of an instrumental part-is contrasted with deeper levels of structure. In other words, if one reduces the second note of the second violin part in $\mathrm{m}$. 8, one gets the motive in its original form, as in $\mathrm{m} .1$.

51 Dittersdorf's opinion of Mozart's quartets is of interest. Dittersdorf considered Mozart's works too complex, a statement directly related to their dense polyphonic quality. See Klorman (2013, 62) for more on this topic. As we see in this and other examples, however, Dittersdorf's own music is also not completely devoid of polyphony. Dittersdorf himself published only six quartets (1789), as opposed the other composers examined here, all if whom wrote many more works in this genre.

52 Other examples of contrast pairs in op. 33 include no. $3 / \mathrm{i}$, subordinate theme (mm. $28 \mathrm{ff})$.

53 In this analysis, a real measure equals $1 \frac{2}{2}$ notated measures. This interpretation is corroborated by the cadences that fall in the mid-measure, such as the first PAC, a situation that usually signals a "compound meter" (see Caplin 2011). I must mention that, in Hepokoski and Darcy's terms (2006, 52), this is a continuous exposition: shortly after the end of my example 15, a PAC occurs with no MC 

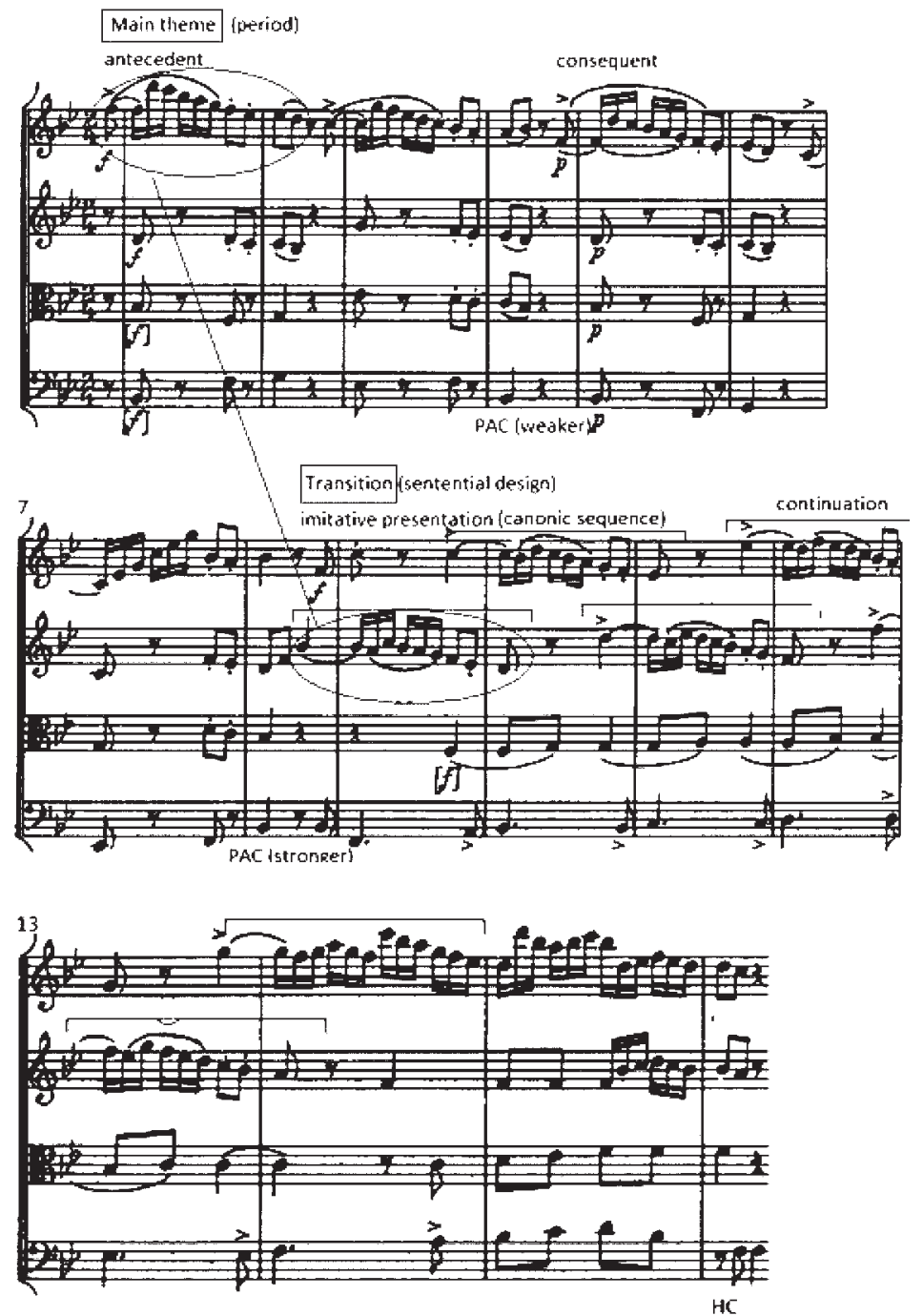

Example 14. Dittersdorf, String Quartet No. 2, in B flat Major/i, main theme and transition

The first violin leads. The transition (m. 13), though it does not repeat the maintheme material exactly, is motivically related to it. In addition to the first violin, other parts imitate the cadential motive of the preceding theme, thus briefly enlivening the texture. Although no significant metrical conflicts occur, the imitations still create a textural contrast with the preceding theme. What is absent from this movement, however, is an embedded contrast pair. Haydn could have used polyphony earlier, perhaps in the recapitulation on the main 

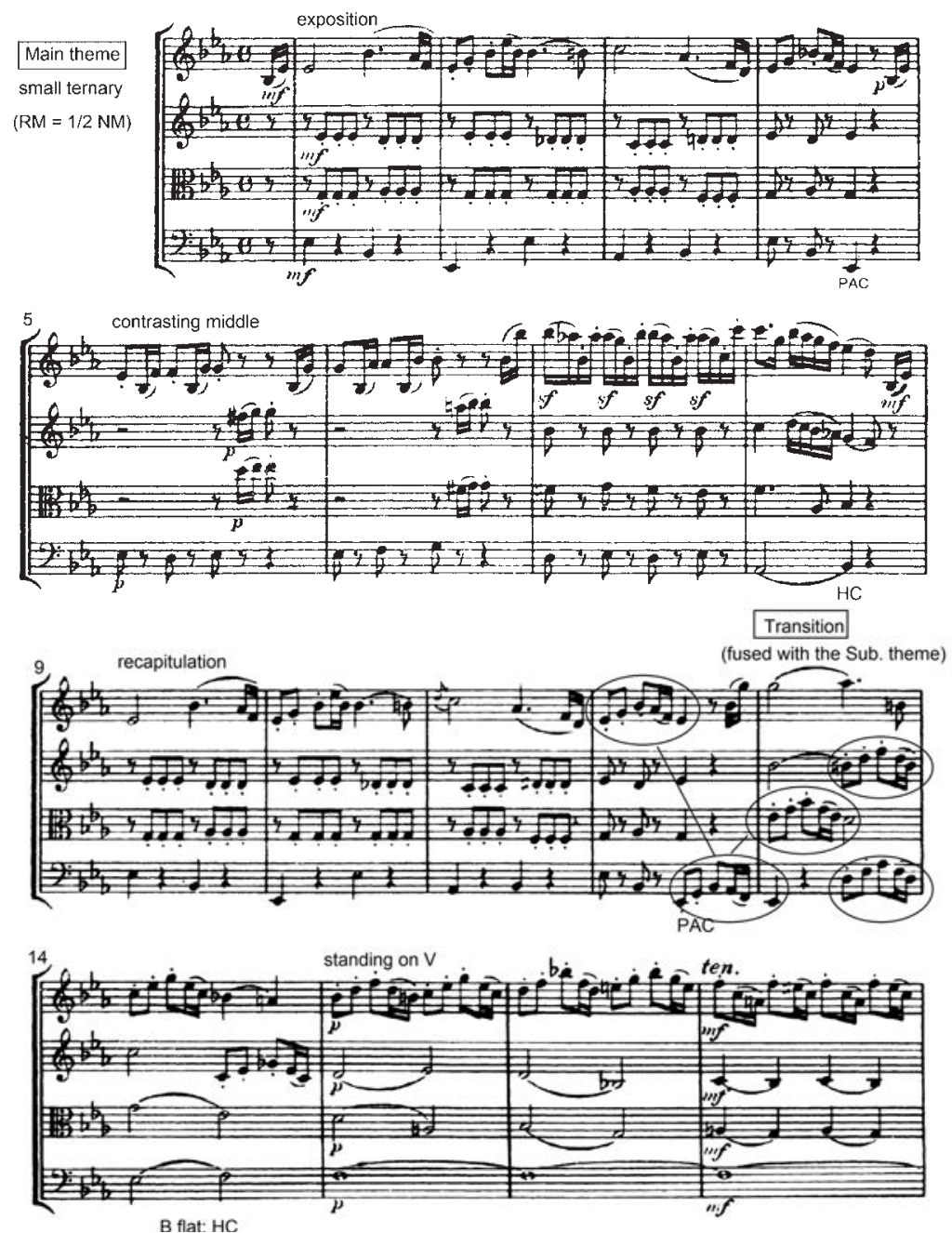

Example 15. Haydn, String Quartet in E-flat Major, op. 33, no. 2/i, main theme and transition

theme (mm. 9-12), thus providing a phrase-level pair. In conjunction with a theme-level pair, an embedded pair would result: exposition/recapitulation at the phrase level (within the small ternary) and main-theme/transition at the theme level.

Op. 33, no. 6/i (example 16) presents another contrast pair. Here, a homophonic main theme (16a) introduces motives that are subsequently used in a considerably looser subordinate theme (16b) in the form of an imitative presentation. The pair differs from most of the Mozart examples in that the imitative presentation does not use the initial motive of the main theme, but rather the one from m. 5 (itself derived from the opening gesture). The motivic process is thus somewhat more complicated than in Mozart's normative contrast pairs. 
a) Main theme, mm. 1-8: period

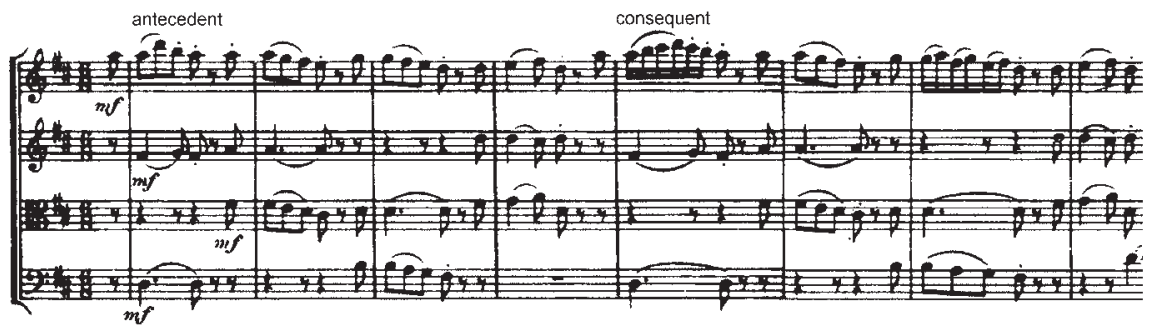

b) Subordinate theme, mm. $27-32$ : imitative presentation

b.i

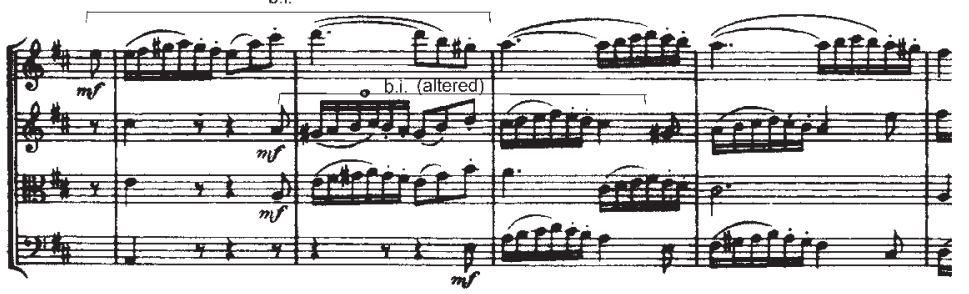

Example 16. Haydn, String Quartet in D Major, op. 33, no. 6/i

Haydn's quartets written after Mozart's "Haydn" quartets, explored earlier in this article, display much more rigorous use of imitative polyphony and the contrast pair principle and may well be a direct result of Mozart's influence. It has been often noted that Haydn and Mozart exerted mutual influence, which is apparent in chamber music and especially the quartets. ${ }^{54}$ It is not surprising, therefore, that Haydn's op. 50 (1787), his first set of quartets written after the appearance of Mozart's set, should feature elements characteristic of the younger composer.

To analyze the entire op. 50 is beyond the scope of this article. Suffice it to say that Haydn uses polyphonic textures much more systematically than he does in his earlier quartets. This fact, combined with the rigorous monothematicism of this opus, gives us several illustrations of contrast groups. 55 One of these instances, a theme-level contrast group, is found in op. 50, no. 6/i (example 17). The main theme begins with a phrase (mm. 1-4) that could serve as a cadence (specifically, the non-tonic opening and the strong V-I progression); the first violin, with its descending motive, dominates the texture. The phrase is followed by an expanded sentence (mm. 5-16). The transition begins with the main theme's opening descending motive, this time without a trace of cadential character but instead structured as an imitative presentation $(\mathrm{mm}$. 16-19). The subordinate theme (m. 26) opens with the same material once again,

54 Einstein $(1962,181)$ says that Mozart learnt from Haydn "as a master form master." BarrettAyres $(1974,377)$ writes, "Haydn and Mozart learnt from each other without giving a single lesson." See Mark Evan Bonds (1993) for a detailed discussion of stylistic, motivic, and other similarities between Haydn's and Mozart's quartets.

55 Barrett-Ayres $(1974,203)$ even entitles the chapter on op. 50 "Monothematicism." 
a) Main theme and transition
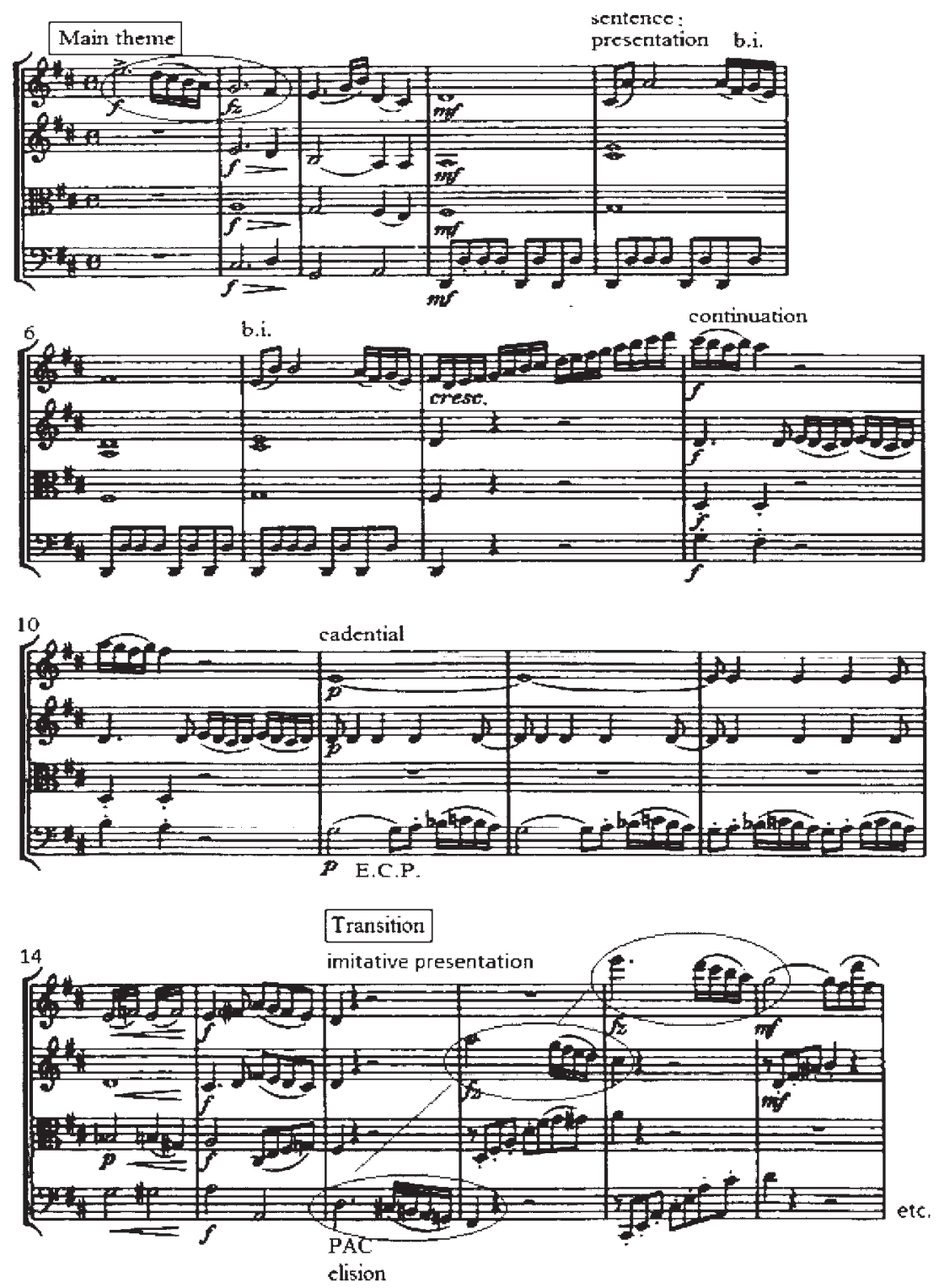

Example 17 (a). Haydn, String Quartet in D Major, op. 50, no. 6/i 
b) Subordinate theme

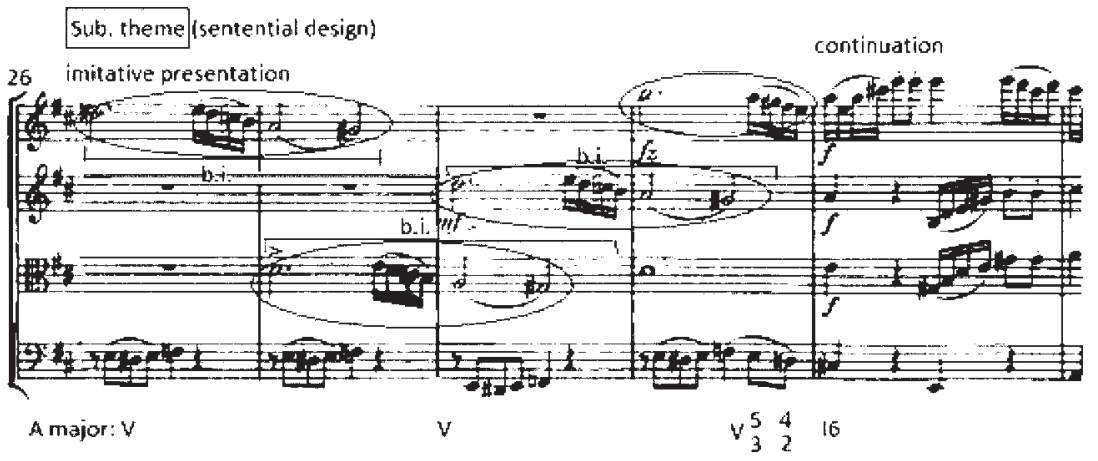

Example 17 (b). Haydn, String Quartet in D Major, op. 50, no. 6/i

though the motive is now slightly changed (the first interval is ascending, rather than descending second), and another imitative presentation results. In sum, this is a contrast group made up of three components, each component being more destabilized than the previous: the transition due to imitative texture, and the subordinate theme due to both its imitative nature and the dominant harmony, prolonged until $\mathrm{m}$. 30 . The technique is remarkably similar to that in Mozart's K. 464/iv (see example 6)..$^{56}$

As Parker has noted, with regard to texture, "Haydn and Mozart seem to have arrived at certain approaches within close chronological proximity ... the genre [of the string quartet] moved smoothly from a first-violin dominated texture to a four-part conversation" (Parker 2002, 279). Her terms "conversation" and "debate" generally refer to what I call polyphony. She then warns against transferring this view to the quartets of other contemporaneous composers. ${ }^{57}$ Indeed, as I have shown, not every quartet composer of the time employs polyphony as much as Haydn and Mozart do; and even when polyphony occurs, contrast groups do not necessarily result. It seems that Mozart was first to explore the contrast-pair principle systematically in his "Haydn" quartets (1785), and that the composer's influence on Haydn is apparent by the consistent use of the technique in his very next quartet opus (op. 50, 1787). It is interesting that, for example, Dittersdorf, who was involved in composing and performing quartets at the same time and place, in his Six Quartets from 1789 (some of which have been analyzed above) was not so much influenced by Mozart's contrast-pair principle. It is true, however, that contrast pairs are only one aspect of the endless richness of compositional techniques employed by the

56 A significant difference, however, is that Mozart's subordinate theme in K. $464 / \mathrm{i}$ is harmonically stable (it is supported by the local tonic of E major), while Haydn's subordinate theme is harmonically destabilized.

57 "The student is thus presented with fairly convincing evidence that the genre [in the music of Haydn and Mozart] moved smoothly from a first-violin dominated texture to a four-part conversation. Many then transfer these generalizations to the quartets of all eighteenth-century composers ... In the process, those works that do not conform are marginalized" (Parker 2002, 279). 
eighteenth-century Viennese masters and that the currents of influence among them worked in many different ways, only some of which pertain to texture.

\section{Conclusion}

Among the textural categories generally accepted pertaining to the music of Mozart and his time-homophony, imitative polyphony, and non-imitative polyphony-imitative polyphony has the highest potential to engender loose formal structures. This compositional possibility results from the grouping and hypermetrical conflicts created by imitative texture. As a result of its loosening ability, imitative texture occurs mostly in medial formal regions at both the phrase and the theme level of formal hierarchy, though imitations are not necessarily restricted to these regions. To connect formal and textural questions with motivic content, we have examined some contrast groups-groups of at least two sections based on shared motivic material and contrasted with each other in formal functionality, formal organization, and texture.

This study does not include all the pairs in the "Haydn" quartets that share motivic material or all the polyphonic activity in these quartets. I paid little attention, for example, to one quartet that displays a fascinating wealth of polyphony and, perhaps as a consequence, a very dramatic character-K. 421 , the only minor-mode piece in the entire set. Rather, I have concentrated on select examples with the purpose of investigating the logic of form-texture relationship that has a broader application in Mozart's oeuvre. Although significant, Mozart does not use polyphony ubiquitously in these quartets. Rather, certain form-functional preferences lie behind his choice for the placement of polyphonically active sections. To a considerable degree, these preferences seem to be Mozart's original contribution to the compositional techniques of the time, for it appears that not many examples of contrast pairs occur in the contemporaneous quartets.

The investigation of polyphony and form allow us approach some theoretical questions that are difficult to examine otherwise. One such question is the link between form-functional theory and motivic analysis. As explicitly stated by Caplin $(1998,4)$, a functional theory of form does not rely on motivic content of music and depends instead on harmony. Traditionally, however, many theories of musical form have strongly relied on motivic analysis, especially those of the nineteenth century..$^{8}$ Furthermore, the notion of motivische Arbeit has been of great significance for the analysis of tonal music in general.59 Therefore, it seems appropriate to associate these two contrasting approaches to from, the harmony-centred and the motivic-centred. The notion of contrast pair provides one possible relationship. It suggests that the formal function

58 In fact, Scott Burnham (2002) characterizes thematic content as the primary concern and the defining feature of the nineteenth-century German theories of form. With regard to nineteenthcentury theorists, see Momigny's analysis of Mozart's quartet K. 421 (1803-6).

59 Though the reliance on thematic material in the twentieth century significantly decreased, it still continues to play a role, as in the work of Charles Rosen (1988 and 1997). 
of beginning fulfils not just harmonically and phrase-structurally expressed formal initiation, as Caplin asserts, but also motivic initiation.

A possible challenge for any study of texture and its structural function may lie in the difficulty of objective criteria for categories of texture. Imitations excluded, deciding whether a passage is homophonic, polyphonic, or a mixture of both is often a matter of subjective judgment, largely because texture remains one of the least defined musical dimensions in terms of its distinct types. Using Leonard Meyer's (1998) differentiation between syntactic musical parameters (those able to display functionally different categories) and statistical ones (those that rely on "amount" rather than on classification), we can situate texture among the statistical parameters. It is more difficult to submit texture to strict categorization, as compared to, say, pitch structure, whereby every single combination (chord) can be related to some harmonic category and a potential tonal function, or to metre, which disposes of many discrete time signatures. Nonetheless, the structural role of imitative polyphony proposed here provides some insight into how texture interacts with form in Mozart's quartets. An awareness of this role enhances our perception of both the large-scale structure and compositional details of these pieces and enriches our experience of this formidably complex music. ${ }^{60}$

\section{WORKs Cited}

Auerbach, Brent. 2008. "Tiered Polyphony and Its Determinative Role in the Piano Music of Johannes Brahms." Journal of Music Theory 52 (2): 273-320. Bakulina, Olga. 2010. Polyphony as a Loosening Technique in Mozart's Haydn Quartets. MA thesis, McGill University.

Barrett-Ayres, Reginald. 1974. Joseph Haydn and the Spring Quartet. New York: Schirmer Books.

Berry, Wallace. 1976. Structural Functions in Music. Englewood Cliffs: Prentice Hall.

Bonds, Mark Evan. 1993. “The Sincerest Form of Flattery? Mozart's 'Haydn' Quartets and the Question of Influence." Studi Musicali 22 (2): 365-409.

Burnham, Scott. 2002. "Form." In The Cambridge History of Western Music Theory, edited by Thomas Christensen, 881-906. Cambridge: Cambridge University Press.

Caplin, William E. 1998. Classical Form: A Theory of Formal Functions for the Instrumental Music of Haydn, Mozart, and Beethoven. New York: Oxford University Press.

_. 2009. "What Are Formal Functions?" In Musical Form, Forms, \& Formenlehre: Three Methodological Reflections, edited by Pieter Bergé, 21-41. Leuven: University of Leuven Press.

—. 2011. "The 'Continuous Exposition' and the Concept of Subordinate Theme." Paper delivered at the Annual Meeting of the Society for Music Theory, Minneapolis.

6o I am very grateful to William Caplin, Edward Klorman, William Rothstein, René Rusch, and two anonymous readers for their valuable advice in the earlier stages of this essay. 
Dittersdorf, Carl Ditters von. (1789a) 1937. String Quartet No. 2 in B-flat Major. Leipzig: Ernst Eulenburg.

- (1789b) 1938. String Quartet No. 1 in D Major. Leipzig: Ernst Eulenburg. - (1789c) 1938. String Quartet No. 5 in E-flat Major. Leipzig: Ernst Eulenburg.

Duane, Ben. 2012. "Texture in Eighteenth- and Early Nineteenth-Century String-Quartet Expositions.” PhD diss., Northwestern University.

Einstein, Alfred. (1945) 1962. Mozart: His Character, His Work. New York: Oxford University Press.

Haydn, Joseph. (1771 and 1781) 1985. String Quartets pp. 20 and 33, Complete. New York: Dover. Reprinted from Ernst Eulenburg, London.

__ [ [1787] 1930. String Quartet in D Major, Op. 50, No. 6. London: Ernst Eulenburg.

Hepokoski, James, and Warren Darcy. 2006. Elements of Sonata Theory: Norms, Types, and Deformations in the Late Eighteenth-Century Sonata. New York: Oxford University Press.

Ivanovitch, Roman. 2010. "Recursive/Discursive: Variation and Sonata in the Andante of Mozart's String Quartet in F, K. 590." Music Theory Spectrum 32 (2): 145-64.

Kirkendale, Warren. 1979. Fugue and Fugato in Rococo and Classical Chamber Music, translated by Margaret Bent and Warren Kirkendale. Durham: Duke University Press.

Klorman, Edward. 2013. "Multiple Agency in Mozart's Music." PhD diss., City University of New York.

Koch, Heinrich Christoph. [1789-93] 1983. Introductory Essay on Composition: The Mechanical Rules of Melody, sections 3 and 4, translated by Nancy Kovaleff Baker. New Haven, CT: Yale University Press.

Kramer, Jonathan. 1988. The Time of Music. New York: Schirmer Books.

Küster, Konrad. 1996. Mozart: A Musical Biography, translated by Mary Whittal. Oxford: Clarendon.

Lerdahl, Fred, and Ray Jackendoff. 1983. A Generative Theory of Tonal Music. Cambridge, MA: MIT Press.

Lester, Joel. 1986. The Rhythms of Tonal Music. Carbondale: Southern Illinois University Press.

Levy, Janet M. 1982. "Texture as Sign in Classical and Romantic Music." Journal of the American Musicological Society 35 (3): 482-531.

Meyer, Leonard B. 1998. "A Universe of Universals." Journal of Musicology 16 (1): $3-25$.

Mirka, Danuta. 2009. Metric Manipulations in Haydn and Mozart. Oxford: Oxford University Press.

Momigny, Jérôme-Joseph. 1803-6. Cours Complet d'harmonie et de composition. 3 volumes. Paris.

Mozart, Wolfgang Amadeus. (1785) 1970. Complete String Quartets. New York: Dover. Reprinted from Breitkopf und Härtel, Leipzig.

Parker, Mara. 2002. The String Quartet, 1750-1797: Four Types of Musical Conversation. Burlington: Ashgate. 
Ratz, Erwin. 1973. Einführung in die musikalische Formenlehre : Über Formprinzipien in den Inventionen und Fugen J.S. Bachs und ihre Bedeutung fur die Kompositionstechnik Beethovens. Vienna: Universal Edition.

Rosen, Charles. 1988. Sonata Forms. New York: Norton.

-1997. The Classical Style: Haydn, Mozart, and Beethoven. New York: Norton.

Rothstein, William. 1989. Phrase Rhythm in Tonal Music. New York: Schirmer Books.

_. 1991. "On Implied Tones." Music Analysis 10 (3): 289-328.

—1995. "Beethoven with and without Kunstgepräng': Metrical Ambiguity Reconsidered." Beethoven Forum 4:165-93.

Sadie, Stanley. 1964. "Mozart, Bach and Counterpoint." Musical Times 105:23-24.

Samarotto, Frank, 1999. "Strange Dimensions: Regularity and Irregularity in Deep Levels of Rhythmic Reduction.” In Schenker Studies 2, edited by Carl Schachter and Heidi Siegel, 222-38. Cambridge: Cambridge University Press.

Schenker, Heinrich. (1935) 1979. Free Composition, translated by Ernst Oster. New York: Longman.

Schoenberg, Arnold. 1967. Fundamentals of Musical Composition, edited by Gerald Strang. London: Faber and Faber.

Schubert, Peter, and Christoph Neidhöfer. 2006. Baroque Counterpoint. Upper Saddle River: Pearson Prentice Hall.

Sutcliffe, Dean. 2003. "Haydn, Mozart, and Their Contemporaries." In The Cambridge Companion to the String Quartet, edited by Robin Stowell, 185209. Cambridge: Cambridge University Press.

Trimmer, Maud Alice. 1981. "Texture and Sonata Form in the Late String Chamber Music of Haydn and Mozart." PhD diss., City University of New York.

Vanhal, Johann Baptist. (1773) 2007. String Quartet in C Major (Bryan C1). London: Merton Music.

—. (1780) 2002. String Quartet in G Major. London: Merton Music. . (1785) 1996. String Quartet in A Major (Bryan A4), Op. 33 No. 2. London: Merton Music.

\begin{abstract}
This essay demonstrates that texture can act as a form-defining factor by focusing on one specific textural type: imitative polyphony. Mozart's six quartets dedicated to Haydn illustrate this claim. Building on William Caplin's form-functional theory and his distinction between tight-knit and loose organization, imitative texture is shown to serve two purposes: as a loosening device, and as a means of textural and phrasestructural contrast. To deepen our understanding of polyphony's formal and expressive roles, two new concepts are proposed: contrast pair and imitative presentation. The contrast-pair principle is then explored in select Viennese quartets by Mozart's contemporaries.
\end{abstract}




\section{RESUMÉ}

Cet article montre que la texture peut fonctionner comme un facteur déterminant la forme, en se penchant sur le cas de la texture de la polyphonie en imitation, dont les six quatuors de Mozart dédiés à Haydn en sont des exemples. En se basant sur la théorie de la forme fonctionnelle de William Caplin et sur sa distinction entre l'organisation serrée et l'organisation libre, on y montre que la texture peut servir deux objectifs : alléger l'organisation, et créer un contraste de texture et de structure de phrase musicale. Afin de mieux comprendre les rôles formels et expressifs de la polyphonie, on y propose deux nouveaux concepts : la paire contrastante et la présentation en imitation. Le principe de paire contrastante est ensuite exploré dans une sélection de quatuors viennois de contemporains de Mozart. 